\title{
ESTUDO DA VEGETAÇÃO COMO SUBSÍDIOS PARA PROPOSTAS DE RECUPERAÇÃO DAS NASCENTES DA BACIA HIDROGRÁFICA DO RIBEIRÃO SANTA CRUZ, LAVRAS, MG ${ }^{1}$
}

Lilian Vilela Andrade Pinto $^{2}$, Soraya Alvarenga Botelho ${ }^{3}$, Ary Teixeira de Oliveira-Filho ${ }^{3}$ e Antonio Claudio Davide ${ }^{3}$

\begin{abstract}
RESUMO - Os objetivos deste estudo foram conhecer a composição florística do estrato arbóreo e regenerativo das nascentes da bacia hidrográfica do ribeirão Santa Cruz e selecionar espécies para serem utilizadas na revegetação das nascentes degradadas e perturbadas da bacia. Os levantamentos florístico e estrutural foram realizados em 12 nascentes. Para a comparação do perfil florístico entre as nascentes, empregaram-se a análise de correspondência retificada (DCA) e a análise de agrupamento de Cluster. A vegetação do estrato arbóreo apresentou maior diversidade nas nascentes perturbadas em relação às degradadas, assim como nas nascentes pontuais em relação às difusas. A similaridade florística do estrato regenerativo entre as nascentes de mesma categoria permitiu inferir que se devem utilizar espécies preferenciais em cada estado de conservação (perturbado ou degradado) e condições do ambiente (solo úmido ou bem drenado) nos programas de recuperação das áreas de preservação permanente das nascentes da bacia hidrográfica do ribeirão Santa Cruz.
\end{abstract}

Palavras-chave: Nascente, mata ciliar, composição florística e recuperação e ambiental, regeneração natural.

\section{STUDY OF THE VEGETATION AS SUBSIDY FOR RECLAMATION PROPOSALS FOR THE SPRINGS OF THE SANTA CRUZ RIVER WATERSHED, LAVRAS, MG BRAZIL}

\begin{abstract}
The objectives of this study were to survey the floristic composition of the arboreal and regenerative stratum of the headwaters of the Santa Cruz River watershed and to select species to be used for reforestation of degraded and disturbed headwaters of the watershed. The floristic and structural surveys were carried out in twelve headwaters. Detrended correspondence analysis (DCA) and cluster analysis were used to compare the floristic profile among the headwaters. The vegetation of the arboreal stratum presented higher diversity in the disturbed than in the degraded headwaters, as well as in the punctual than in the diffuse springs. The floristic similarity of the regenerative stratum among the headwaters of the same category allowed to infer that preferential species should be used for each state of conservation (disturbed or degraded) and environmental condition (humid or well drained soil) in reclamation programs of permanent preservation of headwaters in the Santa Cruz River basin.
\end{abstract}

Keywords: Headwater, riparian forest, floristic composition, environmental reclamation and natural regeneration.

\footnotetext{
${ }^{1}$ Recebido em $1^{\circ} .09 .2003$ e aceito para publicação em 10.08.2005.

${ }^{2}$ Programa de Pós-Graduação em Engenharia Florestal. Departamento de Engenharia Florestal da Universidade Federal de Lavras - 37200-000 Lavras-MG. Caixa Postal 37. E-mail: <lilianvap@ gmail.com>.

33.pepartamentodeEngenhariaFlorestaldaUFLA-Lavras-MGCaixaPostal37.E-mail:<sbotelho@ufla.br>;<aryfilho@ufla.br>;<acdavide@ufla.br>.
} 


\section{INTRODUÇÃO}

A mata ciliar ocupa as áreas mais sensíveis da Bacia Hidrográfica do Ribeirão Santa Cruz, ou seja, localiza-se às margens da rede hidrográfica, ao redor de nascentes e em áreas saturadas, desempenhando influência direta sobre a hidrologia da bacia (ZAKIA, 1998). Segundo Lima (1989), sua presença contribui tanto para diminuir a ocorrência do escoamento superficial, que pode causar erosão e arraste de nutrientes e sedimentos para os cursos d'água, quanto para desempenhar um efeito de filtragem superficial e subsuperficial dos fluxos de água para os canais.

Essas formações vegetais são sistemas particularmente frágeis em face dos impactos promovidos pelo homem, pois, além de conviverem com a dinâmica erosiva e de sedimentação dos cursos d'água, localizamse no fundo de vales (Van Den BERG, 1995), que correspondem às áreas de uma bacia hidrográfica onde, comumente, ocorrem os solos mais férteis e úmidos. Por isso, as matas ciliares são tão propensas a derrubadas, dando lugar às atividades agrícolas (BOTELHO e DAVIDE, 2002; OLIVEIRA FILHO et al., 1994a).

Ao longo dos anos, essas formações vegetais têm sido submetidas a impactos antrópicos devastadores. Como conseqüência, várias regiões do Brasil estão hoje reduzidas a fragmentos esparsos, a maioria profundamente perturbada (CARVALHO et al., 1999), colocando em risco a diversidade das faunas aquática e silvestre (Van Den BERG, 1995).

Para Simões (2001), a recuperação da zona ripária constitui um dos fatores que, conjuntamente com outras práticas conservacionistas, compõem o manejo adequado da bacia hidrográfica, para fins de garantir a quantidade e qualidade da água e a biodiversidade.

Na caracterização física da bacia hidrográfica do Ribeirão Santa Cruz, Pinto et al. (2003) constataram que $85,31 \%$ das 177 nascentes perenes se encontravam em desacordo com o que é estabelecido na alínea c do artigo $2^{\circ}$ do Código Florestal/65, a qual determina preservação permanente: "as florestas e demais formas de vegetação natural localizadas nas nascentes, ainda que intermitentes, e nos chamados olhos d'água, qualquer que seja a situação topográfica, num raio mínimo de 50 (cinquienta) metros de tal forma que proteja a bacia hidrográfica constituinte" (BRASIL, 2002ab). Essa situação aponta a necessidade de recuperação e conservação dessas nascentes.

\section{R. Árvore, Viçosa-MG, v.29, n.5, p.775-793, 2005}

Assim, o objetivo deste estudo foi conhecer a composição florística dos estratos arbóreo e regenerativo das nascentes da Bacia Hidrográfica do Ribeirão Santa Cruz, bem como selecionar espécies a serem utilizadas na revegetação das nascentes degradadas e perturbadas da bacia hidrográfica.

\section{MATERIAL E MÉTODOS}

As nascentes estudadas estão localizadas na Bacia Hidrográfica do Ribeirão Santa Cruz, em Lavras, MG. O município de Lavras apresenta clima do tipo Cwa, temperatura média anual de $19,3^{\circ} \mathrm{C}$, precipitação anual normal de $1.530 \mathrm{~mm}$ e umidade relativa média anual de 76\% (BRASIL, 1992). A formação florestal característica da região é a floresta estacional semidecidual montana (VELOSO et al., 1991).

As nascentes foram classificadas quanto ao tipo de reservatório a que estavam associadas, ou seja, como os lençóis freáticos dão origem às nascentes (CASTRO, 2001), em pontuais ou difusas e, quanto ao grau de conservação em que se encontravam, em perturbadas e degradadas. Como nascentes pontuais foram classificadas aquelas que apresentavam a ocorrência do fluxo d'água em um único local do terreno; como difusas, aquelas que não possuíam um ponto definido no terreno, ou seja, apresentam vários olhos d'água; como perturbadas, aquelas que não possuíam $50 \mathrm{~m}$ de vegetação natural no seu entorno, mas exibiam bom estado de conservação, e como degradadas, aquelas que se encontravam com alto grau de perturbação, muito pouco vegetadas, solo compactado, presença de gado e com erosões e voçorocas.

Visando conhecer as espécies mais adaptadas ao ambiente degradado e perturbado das nascentes, foi realizado o sorteio de três nascentes, levando-se em conta cada uma das seguintes categorias de nascentes: perturbada pontual (PP), perturbada difusa (PD), degradada pontual (DP) e degradada difusa (DD).

Nas 12 nascentes amostradas, a avaliação florística do estrato arbóreo foi feita a partir de quatro parcelas de $500 \mathrm{~m}^{2}(50 \mathrm{~m} \times 10 \mathrm{~m})$ demarcadas acima (R1), abaixo (R2), à direita (R3) e à esquerda (R4) da nascente (Figura 1). Deve-se salientar que a parcela no sentido $R 2$ seguiu o leito do curso d'água, para melhor conhecimento das espécies de ambiente úmido. Em cada parcela foram registrados e identificados todos os indivíduos arbóreos vivos com DAP (diâmetro a altura do peito) $\geq 5 \mathrm{~cm}$. 
Para a avaliação florística do estrato regenerativo, foram demarcadas cinco subparcelas de $20 \mathrm{~m}^{2}$ (10 m x $\left.2 \mathrm{~m}\right)$ equiidistantes $10 \mathrm{~m}$ dentro de cada parcela do estrato arbóreo (Figura I). Foi feito o levantamento florístico de todas as plantas arbóreas com DAP inferior a $5 \mathrm{~cm}$ e altura superior a $10 \mathrm{~cm}$.

O período de coleta se estendeu de abril a outubro de 2002. O material botânico coletado foi identificado pela comparação com exsicatas existentes no Herbário da Universidade Federal de Lavras (Herbário ESAL) e consulta à literatura clássica taxonômica e a especialistas da UFLA. As espécies foram agrupadas em famílias, de acordo com o sistema do Angiosperm Phylogeny Group II (APG II, 2003).

As espécies foram classificadas segundo o seu grupo ecológico, adotando-se a metodologia descrita por Swaine e Whitmore (1988), com modificações sugeridas por Oliveira-Filho et al. (1994b), nas seguintes categorias: pioneiras (P), clímax exigente de luz (L) e clímax tolerante à sombra $(\mathrm{S})$.

A comparação da composição florística das 12 nascentes amostradas foi feita com o intuito de se determinar o grau de similariade florística entre o tipo (pontual ou difusa) e o estado de conservação (degradado ou perturbado) das nascentes. Para a interpretação das relações florísticas entre fragmentos no entorno

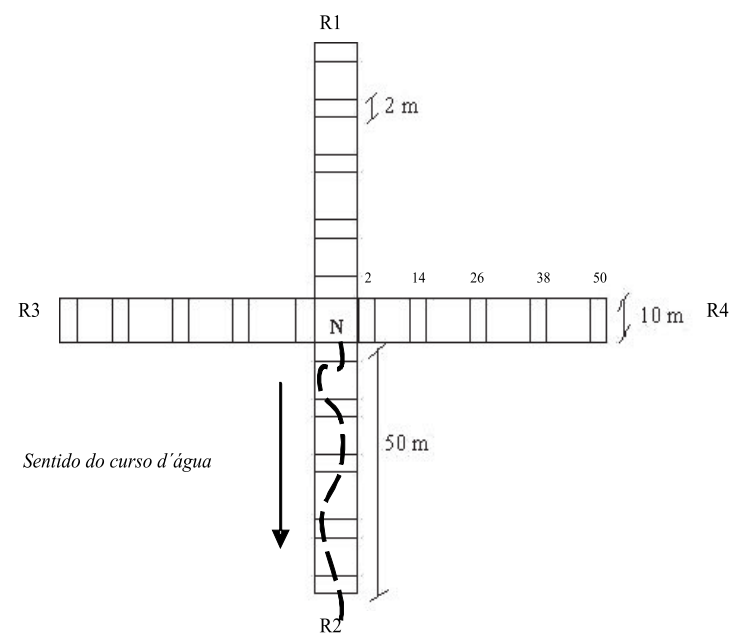

Figura 1 - Locação das parcelas usadas para amostrar os estratos arbóreo e regenerativo.

Figure 1 - Location of plots used for sampling the arboreal and regenerative stratum. das 12 nascentes, foram empregadas a análise de correspondência retificada (DCA) e a análise de agrupamento de "cluster", por meio do cálculo dos coeficientes de similaridade de Jaccard. Ambas as análises foram realizadas pelo programa PC-ORD for Windows versão 4.14 (McCUNE e MEFFORD, 1999), a partir das matrizes de presença/ausência das espécies. Essas matrizes foram compostas pelas espécies presentes em pelo menos três nascentes, uma vez que, segundo Causton (1988), as espécies menos frequientes influenciam muito pouco os padrões emergentes de análises multivariadas de dados quali-quantitativos de vegetação e aumentam, sem necessidade, o volume dos cálculos.

Para a estimativa da diversidade florística ocorrente entre as nascentes e entre as quatro categorias de nascentes em estudo foram utilizados os índices de Shannon-Weaver (H') e de equabilidade de Pielou ( $\left.J^{\prime}\right)$ (BROWER e ZAR, 1984).

Para descrever a estrutura da flora das nascentes foram estimados os parâmetros fitossociológicos clássicos de Mueller-Combois e Ellenberg (1974) de interesse silvicultural, ou seja, a densidade e a frequiência absoluta.

\section{RESULTADOS E DISCUSSÃO}

\section{Composição florística}

A listagem de todas as espécies amostradas nas 12 nascentes é apresentada na Tabela 1.

Nas 12 nascentes amostradas foram identificados 6.851 indivíduos, distribuídos em 224 espécies, 127 gêneros e 54 famílias botânicas. Dentro das parcelas para a avaliação do estrato arbóreo (A) foram amostrados 1.836 indivíduos, distribuídos em 120 espécies e 44 famílias, resultando em uma densidade média de 1.279 indivíduos/ha. Nas parcelas para avaliação do estrato regenerativo $(\mathrm{R})$ foram amostrados 5.016 indivíduos, distribuídos em 210 espécies e 51 famílias, resultando em uma densidade média de 9.450 indivíduos/ha.

As nascentes perturbadas, além de terem apresentado maior número de espécies (176) em relação às nascentes degradadas (143), apresentaram ainda uma densidade bem superior, tanto no estrato arbóreo quanto no estrato regenerativo (Tabela 2). Esses dados confirmam o grau de perturbação observado na classificação dada às nascentes.

R. Árvore, Viçosa-MG, v.29, n.5, p.775-793, 2005 
Tabela 1 - Relação das espécies arbustivo-arbóreas registradas nas nascentes da bacia hidrográfica do ribeirão Santa Cruz, em Lavras, MG. As espécies presentes no estrato regenerativo (R) e no estrato arbóreo (A) das nascentes degradadas, difusas (DD) e pontuais (DP), das perturbadas, difusas (PD) e pontuais (PP) encontram-se acompanhadas de sua família, nome científico, número de registro no Herbário ESAL e grupo ecológico (GE): pioneiras $(\mathrm{P})$, secundárias (S), clímax (L) e não classificadas (nc)

Table 1 - List of shrub-tree species registered in the springs of the Santa Cruz River watershed, Lavras, MG - Brazil. The species present in the regenerative stratum $(R)$ and in the arboreal stratum $(A)$ of the diffuse-degraded $(D D)$, punctualdegraded $(D P)$, diffuse-disturbed $(P D)$ and punctual-disturbed $(P P)$ spring, came with their family, scientific name, registration number at the ESAL Herbarium, and ecological species group $(G E)$ : pioneers $(P)$, secondary $(S)$, climax (L) and not classified (nc)

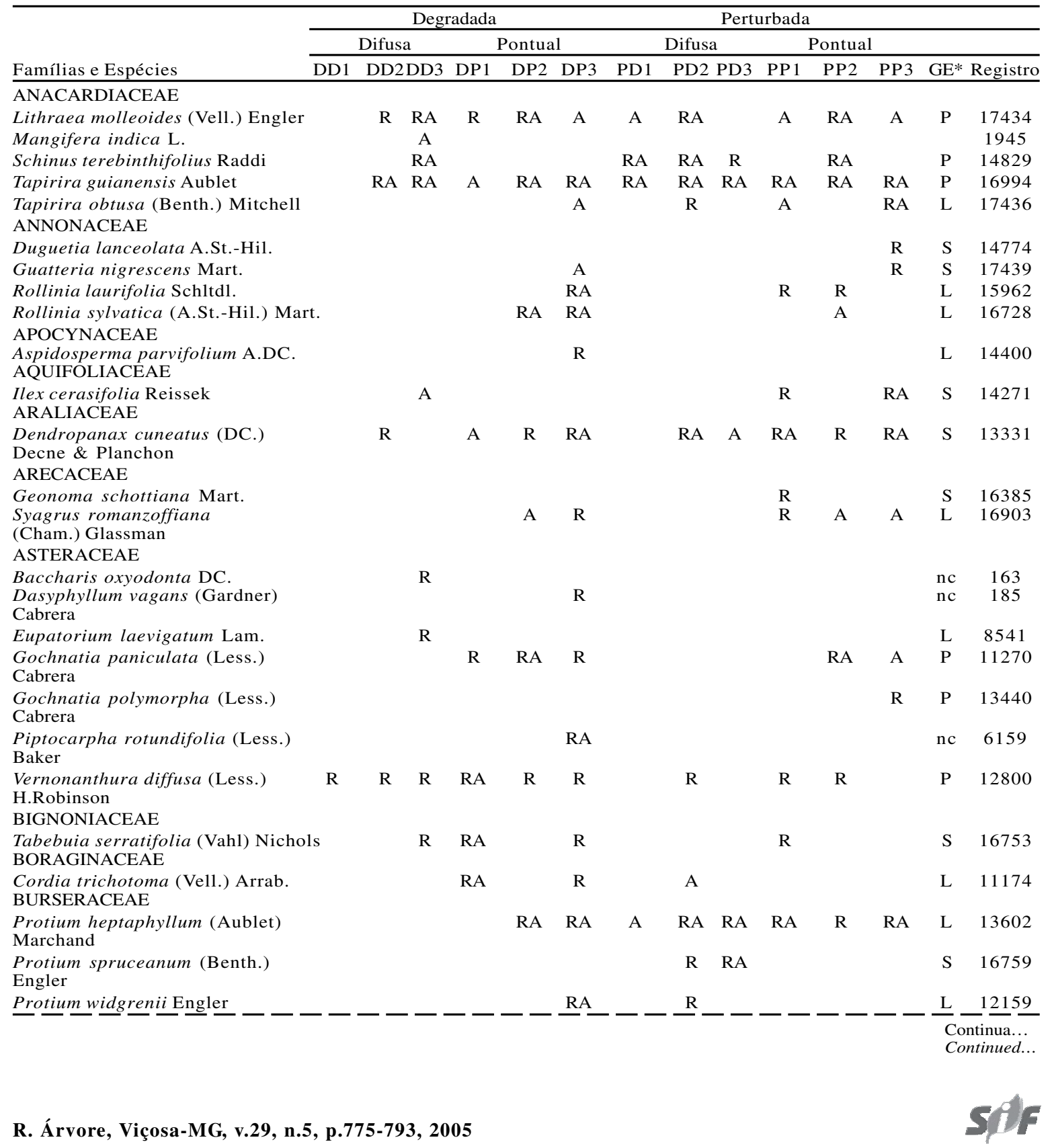


Tabela 1 - Cont

Table 1 - Cont

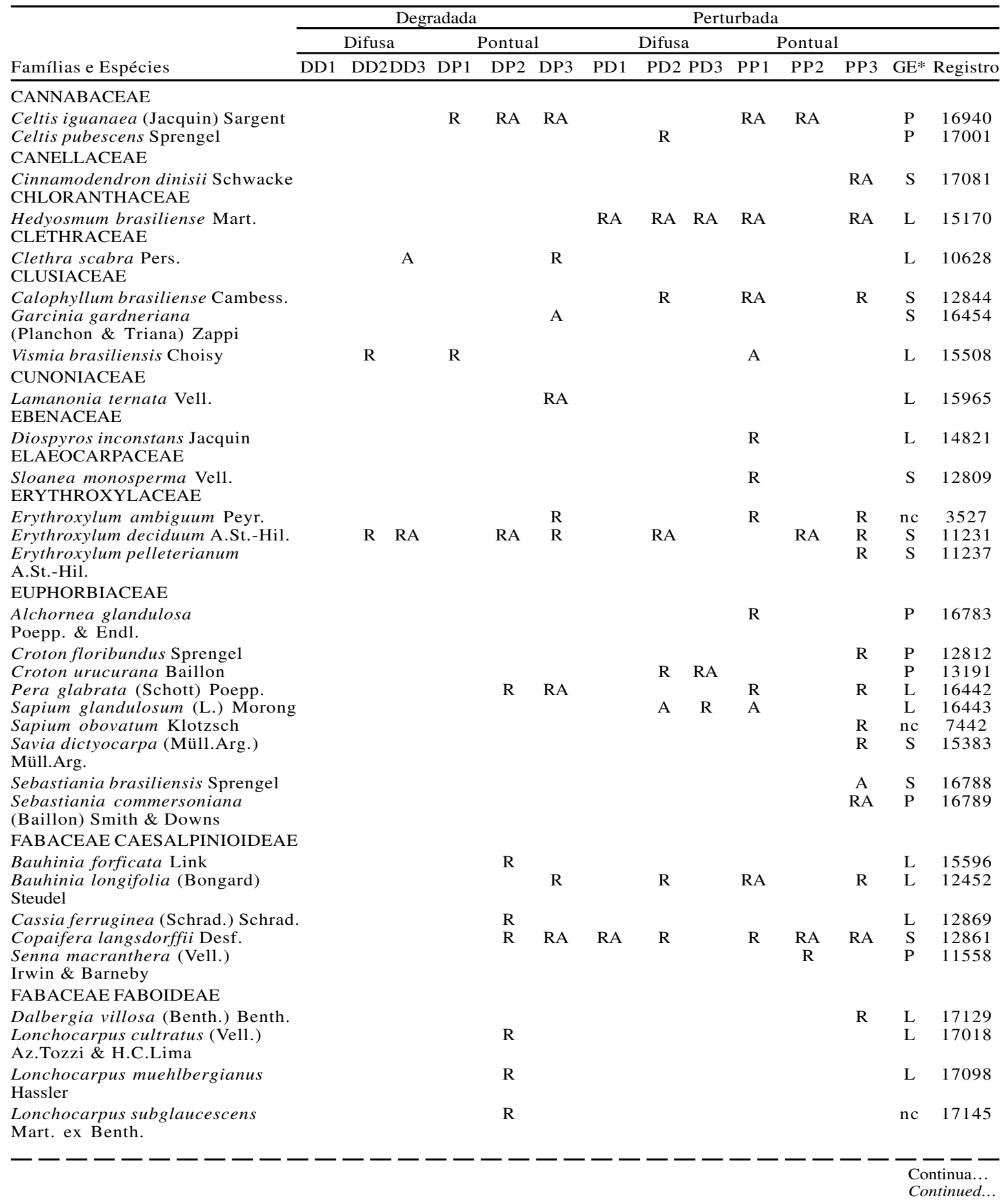

R. Árvore, Viçosa-MG, v.29, n.5, p.775-793, 2005 
Tabela 1 - Cont

Table 1 - Cont

\begin{tabular}{|c|c|c|c|c|c|c|c|c|c|c|c|c|}
\hline \multirow[b]{3}{*}{ Famílias e Espécies } & \multicolumn{5}{|c|}{ Degradada } & \multicolumn{5}{|c|}{ Perturbada } & & \\
\hline & & Difusa & & Pontua & & & Difusa & & ontua & & & \\
\hline & DD1 & DD2DD3 & DP1 & DP2 & DP3 & PD1 & PD2 PD3 & PP 1 & PP2 & PP3 & $\mathrm{GE}^{*}$ & Registro \\
\hline
\end{tabular}

FABACEAE FABOIDEAE

D1

Machaerium brasiliense Vogel

Machaerium hirtum (Vell.) Stellfeld

Machaerium nictitans (Vell.) Benth. A

Machaerium stipitatum (DC.) Vogel

Machaerium villosum Vogel

Platypodium elegans Vogel

FABACEAE MIMOSOIDEAE

Acacia glomerosa Benth.

Albizia polycephala (Benth.) Killip

Inga striata Benth.

Piptadenia gonoacantha

(Mart.) Macbr.

Xylosma ciliatifolium (Clos) Eichler

Xylosma prockia (Turcz.) Turcz.

ICACINACEAE

Citronella paniculata (Mart.)

Howard

LACISTEMATACEAE

Lacistema hasslerianum Chodat

LAURACEAE

Aiouea costaricensis (Mez) Kosterm.

Aniba firmula (Nees \& Mart.) Mez

Cinnamomum glaziovii (Mez)

Vattimo

Endlicheria paniculata (Sprengel)

Macbr.

Laurus nobilis $\mathrm{L}$.

Nectandra grandiflora Nees

Nectandra nitidula Nees

Nectandra oppositifolia Nees

Ocotea corymbosa (Meisner) Mez

Ocotea dispersa (Nees) Mez

Ocotea odorifera (Vell.) Rohwer

Ocotea puberula (Rich.) Nees

Ocotea pulchella Mart.

Ocotea silvestris Vattimo

Ocotea velutina (Nees) Rohwer

Persea pyrifolia Nees \& Mart.

Persea venosa Nees \& Mart.

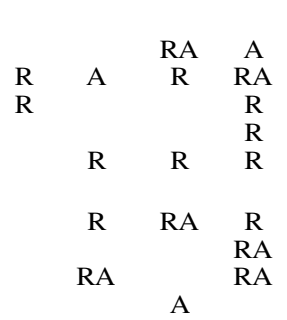

A

GANIACEAE

Strychnos brasiliensis (Sprengel)

Mart.

LYTHRACEAE

Lafoensia pacari A.St.-Hil.

MAGNOLIACEAE

Talauma ovata A.St.-Hil.

MALPIGHIACEAE

Byrsonima coccolobaefolia Kunth Byrsonima laxiflora Griseb.

Heteropterys byrsonimifolia A.Juss.

MALVACEAE

Luehea divaricata Mart. \& Zucc.

MELASTOMATACEAE

Leandra aurea (Cham.) Cogn.

Leandra gardneriana Cogn.
$\mathrm{R}$
$\mathrm{R}$

\begin{tabular}{|c|c|c|c|}
\hline \multirow{11}{*}{$\begin{array}{l}\mathrm{R} \\
\mathrm{R}\end{array}$} & & RA & A \\
\hline & A & $\mathrm{R}$ & RA \\
\hline & & & $\mathrm{R}$ \\
\hline & & & $\mathrm{R}$ \\
\hline & $\mathrm{R}$ & $\mathrm{R}$ & $\mathrm{R}$ \\
\hline & $\mathrm{R}$ & $\mathrm{RA}$ & $\mathrm{R}$ \\
\hline & & & RA \\
\hline & RA & & RA \\
\hline & & A & \\
\hline & $\mathrm{R}$ & & \\
\hline & $\mathrm{R}$ & & \\
\hline
\end{tabular}

$\mathrm{R}$

$\mathrm{R}$
R $\quad$ RA

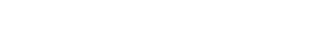

RA

$\mathrm{R}$

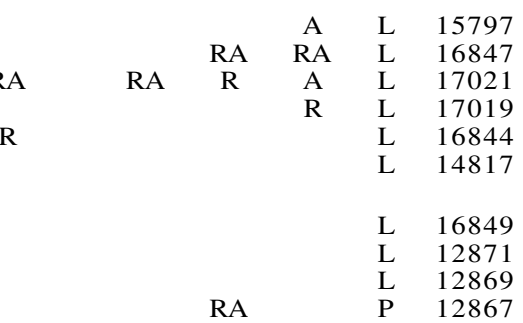

$\begin{array}{lll}\mathrm{R} & \mathrm{L} & 17288 \\ \mathrm{R} & \mathrm{L} & 12837\end{array}$

R RA S 12388

RA S 17110

R RA S

RA $\quad$ R

R. Árvore, Viçosa-MG, v.29, n.5, p.775-793, 2005 
Tabela 1 - Cont

Table 1 - Cont

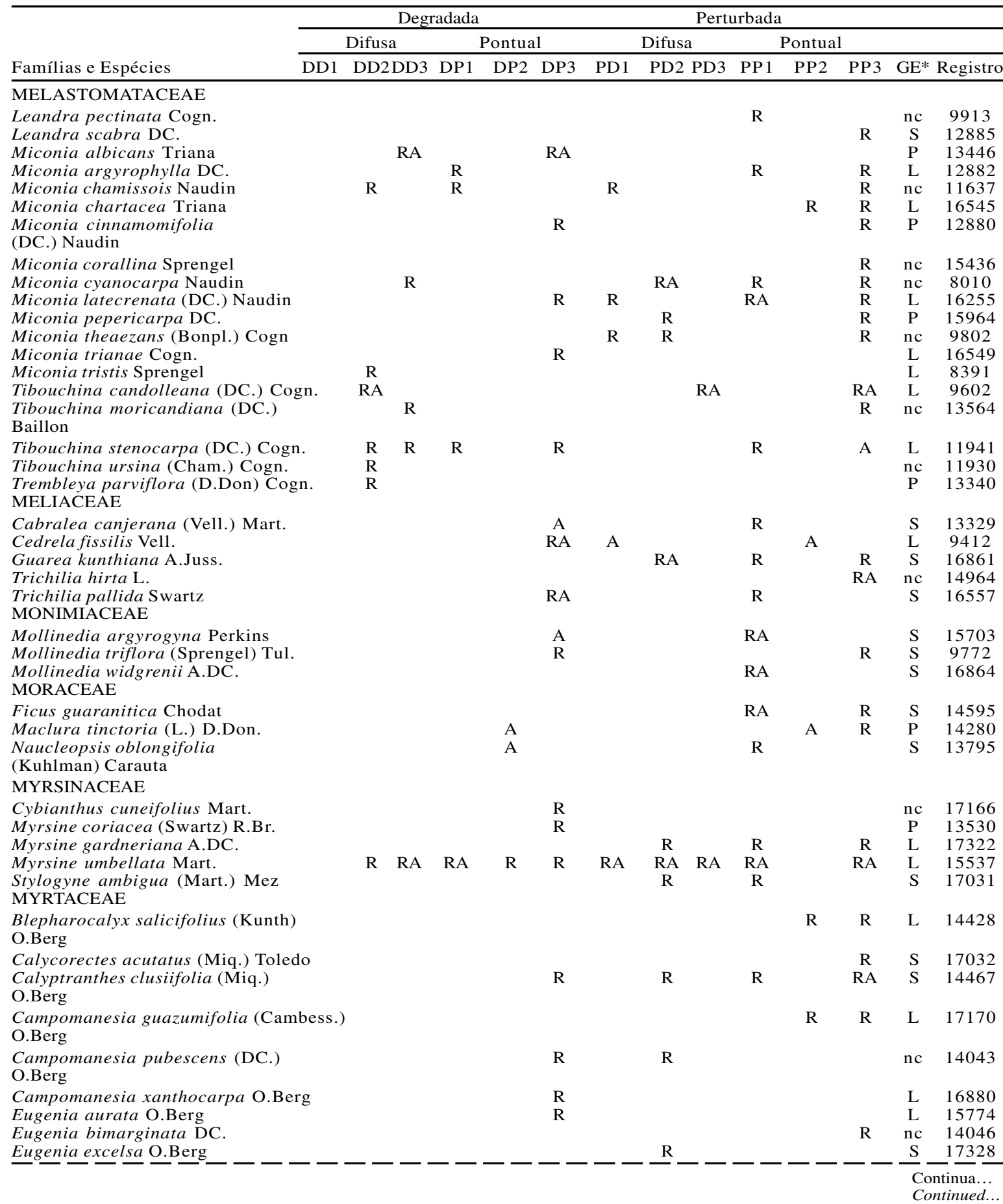

R. Árvore, Viçosa-MG, v.29, n.5, p.775-793, 2005 
Tabela 1 - Cont

Table 1 - Cont

\begin{tabular}{|c|c|c|c|c|c|c|c|c|c|c|c|c|c|c|}
\hline \multirow[b]{3}{*}{ Famílias e Espécies } & \multicolumn{6}{|c|}{ Degradada } & \multicolumn{6}{|c|}{ Perturbada } & \multirow[b]{3}{*}{ GE* } & \multirow[b]{3}{*}{ Registro } \\
\hline & \multicolumn{3}{|c|}{ Difusa } & \multicolumn{3}{|c|}{ Pontual } & \multicolumn{3}{|c|}{ Difusa } & \multicolumn{3}{|c|}{ Pontual } & & \\
\hline & DD1 & DD2 & DD3 1 & DP1 & $\mathrm{DP} 2$ & DP3 & PD1 & PD2 & PD3 & PP1 & $\mathrm{PP} 2$ & PP3 & & \\
\hline \multicolumn{15}{|l|}{ MYRTACEAE } \\
\hline Eugenia florida DC. & & & & & & A & & $\mathrm{R}$ & & & $\mathrm{R}$ & RA & $S$ & 12925 \\
\hline Eugenia handroana D.Legrand & & & & & & $\mathrm{R}$ & & & & & & & $\mathrm{S}$ & 17330 \\
\hline Eugenia hyemalis Cambess. & & & & & & & & $\mathrm{R}$ & & & & RA & $\mathrm{L}$ & 16883 \\
\hline Eugenia obversa O. Berg & & & & & & $\mathrm{R}$ & & & & & & & $\mathrm{nc}$ & 16475 \\
\hline Eugenia punicifolia (Kunth) DC. & & $\mathrm{R}$ & & & & & & & & & & & $\mathrm{L}$ & 12084 \\
\hline Eugenia subavenia O.Berg & & & & & & & & & & & & $\mathrm{R}$ & $\mathrm{S}$ & 17332 \\
\hline $\begin{array}{l}\text { Gomidesia affinis (Cambess.) } \\
\text { D.Legrand }\end{array}$ & & & & & & A & & & & & & & $\mathrm{L}$ & 12932 \\
\hline $\begin{array}{l}\text { Myrceugenia bracteosa (DC.) } \\
\text { D.Legrand \& Kausel }\end{array}$ & & & & & & & & $\mathrm{R}$ & & & & A & $\mathrm{L}$ & 15349 \\
\hline Myrcia fallax (Rich.) DC. & & & & & & $\mathrm{R}$ & & & & $\mathrm{R}$ & A & & $\mathrm{L}$ & 12929 \\
\hline $\begin{array}{l}\text { Myrcia guianensis (Aublet) DC. } \\
\text { Myrcia laruotteana Cambess. }\end{array}$ & & & $\mathrm{R}$ & & & & & & & & $\mathrm{R}$ & & $\begin{array}{l}\mathrm{L} \\
\mathrm{L}\end{array}$ & $\begin{array}{l}14051 \\
17337\end{array}$ \\
\hline Myrcia rostrata $\mathrm{DC}$. & & & & & & $\mathrm{R}$ & & & & $\mathrm{R}$ & & & $\mathrm{L}$ & 17176 \\
\hline Myrcia tomentosa (Aublet) DC. & & & $\mathrm{R}$ & RA & A & & & & & $\mathrm{R}$ & $\mathrm{R}$ & $\mathrm{R}$ & $\mathrm{L}$ & 14044 \\
\hline Myrcia velutina O.Berg & & $\mathrm{R}$ & $\mathrm{R}$ & & & $\mathrm{R}$ & & & & A & & RA & $\mathrm{L}$ & 9764 \\
\hline Myrcia venulosa DC. & & $\mathrm{R}$ & & & & RA & & & & & RA & RA & $\mathrm{L}$ & 16893 \\
\hline Myrciaria tenella (DC.) O.Berg & & & & & & & & & & & & $\mathrm{R}$ & $\mathrm{S}$ & 17340 \\
\hline $\begin{array}{l}\text { Pimenta pseudocaryophyllus } \\
\text { (Gomes) Landrum }\end{array}$ & & & & & & & A & & & & RA & $\mathrm{RA}$ & $\mathrm{L}$ & 12933 \\
\hline Psidium cattleyanum Sabine & & & $\mathrm{P}$ & & & RA & & $\mathrm{RA}$ & & & & A & $\mathrm{L}$ & $\begin{array}{l}16483 \\
10839\end{array}$ \\
\hline Psidium guajava L. & & & & & $\mathrm{R}$ & N & & ה & & & & $\mathrm{R}$ & $\mathrm{L}$ & 16897 \\
\hline Psidium rufum Mart. & & & & & & & & & & $\mathrm{R}$ & & $\mathrm{R}$ & $\mathrm{L}$ & 16898 \\
\hline Siphoneugena densiflora O.Berg & & $\mathrm{R}$ & & & & $\mathrm{R}$ & & & & $\mathrm{R}$ & & $\mathrm{R}$ & $\mathrm{s}$ & 16899 \\
\hline $\begin{array}{l}\text { Siphoneugena kiaerskoviana } \\
\text { (Burret) Kausel }\end{array}$ & & & & & & & & $\mathrm{R}$ & & & & $\mathrm{R}$ & S & 16896 \\
\hline \multicolumn{15}{|l|}{ OLACACEAE } \\
\hline $\begin{array}{l}\text { Heisteria silvianii Schwacke } \\
\text { ONAGRACEAE }\end{array}$ & & & & & & & & & & & & A & S & 17182 \\
\hline $\begin{array}{l}\text { Ludwigia laruotteana (Cambess.) } \\
\text { H. Hara }\end{array}$ & & & & & $\mathrm{R}$ & & & & & & & & $\mathrm{nc}$ & 7274 \\
\hline $\begin{array}{l}\text { Ludwigia nervosa (Poir) Hara } \\
\text { Ludwigia suffruticosa Walter } \\
\text { PHYLLANTHACEAE }\end{array}$ & & $\mathrm{R}$ & & & & $\mathrm{R}$ & & $\mathrm{R}$ & & & & & $\begin{array}{l}\mathrm{nc} \\
\mathrm{nc}\end{array}$ & $\begin{array}{l}13573 \\
8468\end{array}$ \\
\hline $\begin{array}{l}\text { Hyeronima alchorneoides Fr.Allem } \\
\text { Hyeronima ferruginea Müll.Arg. } \\
\text { PIPERACEAE }\end{array}$ & & & A & & & $\begin{array}{l}\mathrm{A} \\
\mathrm{A}\end{array}$ & & RA & RA & RA & & A & $\begin{array}{l}\mathrm{L} \\
\mathrm{L}\end{array}$ & $\begin{array}{l}15379 \\
12835\end{array}$ \\
\hline $\begin{array}{l}\text { Piper aduncum L. } \\
\text { Piper caldense C.DC. } \\
\text { Piper mikanianum (Kunth) Steud. } \\
\text { PROTEACEAE }\end{array}$ & $\mathrm{R}$ & $\mathrm{R}$ & $\begin{array}{l}\mathrm{R} \\
\mathrm{R}\end{array}$ & $\mathrm{R}$ & $\begin{array}{l}\mathrm{R} \\
\mathrm{R}\end{array}$ & $\mathrm{R}$ & $\mathrm{R}$ & $\mathrm{R}$ & $\begin{array}{l}\mathrm{R} \\
\mathrm{R} \\
\mathrm{R}\end{array}$ & $\mathrm{R}$ & $\mathrm{R}$ & $\mathrm{R}$ & $\begin{array}{l}\mathrm{P} \\
\mathrm{nc} \\
\mathrm{nc}\end{array}$ & $\begin{array}{l}14831 \\
17186 \\
16568\end{array}$ \\
\hline $\begin{array}{l}\text { Roupala montana Aublet } \\
\text { ROSACEAE }\end{array}$ & & & & & & A & & & & & & & $\mathrm{L}$ & 16908 \\
\hline $\begin{array}{l}\text { Prunus brasiliensis (Cham. \& Schlt } \\
\text { D.Dietr. }\end{array}$ & tdl.) & & & & & & & & & $\mathrm{R}$ & & & S & 16910 \\
\hline $\begin{array}{l}\text { Prunus myrtifolia (L.) Urban } \\
\text { RUBIACEAE }\end{array}$ & & & & & & & & $\mathrm{R}$ & & $\mathrm{R}$ & & & S & 16574 \\
\hline $\begin{array}{l}\text { Alibertia concolor (Cham.) } \\
\text { K.Schum. }\end{array}$ & & & & & & RA & & & & $\mathrm{R}$ & & RA & $\mathrm{L}$ & 16911 \\
\hline Alibertia myrciifolia K.Schum. & & & & & & RA & & & & & & & $\mathrm{L}$ & 15363 \\
\hline Amaioua guianensis Aublet & & & & & & & & & & & & RA & $\mathrm{S}$ & 13204 \\
\hline $\begin{array}{l}\text { Bathysa meridionalis L.B. } \\
\text { Sm. \& Downs }\end{array}$ & & & & & & & & & & $\mathrm{R}$ & & & $\mathrm{nc}$ & 15360 \\
\hline Chomelia sericea Müll.Arg. & & & & & RA & & & & & & A & RA & S & 13722 \\
\hline & & & & & & & & & & & & & & ontinua... \\
\hline
\end{tabular}


Tabela 1 - Cont

Table 1 - Cont

\begin{tabular}{|c|c|c|c|c|c|c|c|c|c|c|c|c|c|c|}
\hline \multirow[b]{3}{*}{ Famílias e Espécies } & \multicolumn{6}{|c|}{ Degradada } & \multicolumn{6}{|c|}{ Perturbada } & \multirow[b]{3}{*}{ GE* } & \multirow[b]{3}{*}{ Registro } \\
\hline & \multicolumn{3}{|c|}{ Difusa } & \multicolumn{3}{|c|}{ Pontual } & \multicolumn{3}{|c|}{ Difusa } & \multicolumn{3}{|c|}{ Pontual } & & \\
\hline & $\overline{\text { DD1 }}$ & DD21 & DD3 & DP1 & DP2 & DP3 & PD1 & PD2 & PD3 & PP1 & PP2 & PP3 & & \\
\hline \multicolumn{15}{|l|}{ RUBIACEAE } \\
\hline Coffea arabica $\mathrm{L}$. & & & & & & $\mathrm{R}$ & & & & $\mathrm{R}$ & & & $\mathrm{nc}$ & 14652 \\
\hline Faramea cyanea Müll.Arg. & & & & & & $\mathrm{R}$ & & & & $\mathrm{R}$ & & A & $\mathrm{S}$ & 12954 \\
\hline Faramea multiflora A.Rich. & & & & & & & & RA & & $\mathrm{R}$ & & & $\mathrm{S}$ & 12953 \\
\hline Guettarda uruguensis & & & & $\mathrm{R}$ & $\mathrm{R}$ & A & & & & & & & $\mathrm{L}$ & 16916 \\
\hline \multicolumn{15}{|l|}{ Cham. \& Schltdl. } \\
\hline Ixora warmingii Müll.Arg. & & & & & & & & & & $\mathrm{R}$ & & & $\mathrm{S}$ & 16917 \\
\hline Psychotria barbiflora DC. & & & & & & $\mathrm{R}$ & & & & $\mathrm{R}$ & & & $\mathrm{nc}$ & 12551 \\
\hline Psychotria capitata $\mathrm{Ru}$ & & & & & & & & & & & & $\mathrm{R}$ & $\mathrm{nc}$ & 16707 \\
\hline Psychotria carthagenensis Jacquin & & & & & & & & & & $\mathrm{R}$ & & $\mathrm{R}$ & $\mathrm{S}$ & 15566 \\
\hline Psychotria deflexa DC. & & & & & & & & & & $\mathrm{R}$ & & & $\mathrm{S}$ & 14507 \\
\hline \multirow{2}{*}{\multicolumn{2}{|c|}{$\begin{array}{l}\text { Psychotria sessilis (Vell.) Müll.Arg. } \\
\text { Rudgea viburnoides (Cham.) Benth. } \\
\text { RUTACEAE }\end{array}$}} & & $\mathrm{R}$ & & & RA & & A & $\mathrm{R}$ & $\mathrm{R}$ & & & $\mathrm{P}$ & 16588 \\
\hline & & & & $\mathrm{R}$ & & & & A & & & & A & $\mathrm{L}$ & 15187 \\
\hline \multicolumn{2}{|l|}{$\begin{array}{l}\text { Esenbeckia febrifuga (A.St.-Hil.) } \\
\text { A.Juss. }\end{array}$} & & & & $\mathrm{R}$ & & & $\mathrm{R}$ & & RA & $\mathrm{R}$ & & $\mathrm{S}$ & 16592 \\
\hline \multicolumn{2}{|l|}{$\begin{array}{l}\text { Galipea jas } \\
\text { Engler }\end{array}$} & & & & & & & & & $\mathrm{R}$ & & & $\mathrm{S}$ & 16593 \\
\hline \multicolumn{2}{|l|}{$\begin{array}{l}\text { Metrodorea stipularis Mart. } \\
\text { Zanthoxylum rhoifolium Lam. } \\
\text { SALICACEAE }\end{array}$} & $\mathrm{R}$ & & $\mathrm{R}$ & RA & RA & A & & & $\mathrm{R}$ & $\mathrm{R}$ & $\mathrm{R}$ & $\begin{array}{l}\mathrm{S} \\
\mathrm{L}\end{array}$ & $\begin{array}{l}16923 \\
9414\end{array}$ \\
\hline \multicolumn{2}{|l|}{ Casearia arborea (L.C.Rich.) Urban } & & & & & & & & & $\mathrm{R}$ & & & $\mathrm{L}$ & 13460 \\
\hline \multicolumn{2}{|l|}{ Casearia decandra Jacquin } & $\mathrm{R}$ & $\mathrm{R}$ & & $\mathrm{R}$ & $\mathrm{R}$ & & $\mathrm{R}$ & & $\mathrm{R}$ & RA & RA & $\mathrm{S}$ & 12396 \\
\hline \multicolumn{2}{|l|}{ Casearia lasiophylla Eichler } & & & & & RA & & & & $\mathrm{R}$ & & & $\mathrm{L}$ & 9614 \\
\hline \multicolumn{2}{|l|}{ Casearia sylvestris Swartz } & $\mathrm{R}$ & $\mathrm{R}$ & RA & RA & $\mathrm{R}$ & $\mathrm{R}$ & & & RA & RA & $\mathrm{R}$ & $\mathrm{P}$ & 12201 \\
\hline $\begin{array}{l}\text { Casearia ulmifolia } \text { Vahl } \\
\text { SAPINDACEAE }\end{array}$ & & & & & & & & & & & & $\mathrm{R}$ & $\mathrm{nc}$ & 16685 \\
\hline Cupania vernalis Cambess. & & & & & & $\mathrm{R}$ & & & & & $\mathrm{R}$ & & $\mathrm{L}$ & 15958 \\
\hline $\begin{array}{l}\text { Matayba elaeagnoides Radlk. } \\
\text { SAPOTACEAE }\end{array}$ & & & & & & A & & & & $\mathrm{R}$ & & & $\mathrm{L}$ & 13330 \\
\hline $\begin{array}{l}\text { Chrysophyllum marginatum } \\
\text { (Hooker \& Arnot) Radlk. }\end{array}$ & & & & $\mathrm{R}$ & $\mathrm{R}$ & $\mathrm{R}$ & $\mathrm{R}$ & & & RA & RA & RA & $\mathrm{L}$ & 13207 \\
\hline $\begin{array}{l}\text { STPARUNACEAE } \\
\text { Siparuna cujabana (Mart.) A.DC. }\end{array}$ & & & & & & A & & & $\mathrm{R}$ & $\mathrm{R}$ & & RA & $\mathrm{nc}$ & 1316 \\
\hline $\begin{array}{l}\text { Siparuna guianensis Aublet } \\
\text { SOLANACEAE }\end{array}$ & & & & & & RA & & $\mathrm{R}$ & & & RA & $\mathrm{R}$ & $\mathrm{S}$ & 12471 \\
\hline Cestrum laevigatum Schltdl. & & & & & & $\mathrm{R}$ & & $\mathrm{R}$ & $\mathrm{R}$ & $\mathrm{R}$ & & & $\mathrm{S}$ & 16931 \\
\hline Solanum bullatum Vell. & & & & & & & & & & & $\mathrm{R}$ & & $\mathrm{L}$ & 17393 \\
\hline Solanum granuloso-leprosum Duna & & & & $\mathrm{R}$ & & & & & & A & & & $\mathrm{P}$ & 040 \\
\hline Solanum leucodendror & & & & & & A & & & & & & & $\mathrm{L}$ & 17218 \\
\hline Solanum lyco & & & $\mathrm{R}$ & RA & & $\mathrm{R}$ & & & & & $\mathrm{R}$ & & $\mathrm{nc}$ & 16933 \\
\hline Solanum pseudoquina A.St.-Hil. & & & & A & & $\mathrm{R}$ & & & & $\mathrm{R}$ & & & $\mathrm{L}$ & 15482 \\
\hline $\begin{array}{l}\text { Solanum swartzianum } \\
\text { Roem. \& Schult. }\end{array}$ & & & & & & & & $\mathrm{R}$ & & & & & $\mathrm{L}$ & 15481 \\
\hline STYRACACEAE & & & & & & & & & & & & & & \\
\hline Styrax camporus Pohl & & $\mathrm{R}$ & & & & & & & & $\mathrm{R}$ & & & $\mathrm{L}$ & 13285 \\
\hline Styrax ferrugineus Nees \& Mart. & & & & & $\mathrm{R}$ & & & & & & & & $\mathrm{L}$ & 15199 \\
\hline Styrax pohlii A.DC. & & & & & & RA & & & & & & & $\mathrm{nc}$ & 12965 \\
\hline $\begin{array}{l}\text { SYMPLOCACEAE } \\
\text { Symplocos pubescens Klotzsch } \\
\text { ULMACEAE }\end{array}$ & & & & & & & & $\mathrm{R}$ & & & & & $\mathrm{L}$ & 16937 \\
\hline $\begin{array}{l}\text { Trema micrantha }(\mathrm{L} .) \text { Blume } \\
\text { URTICACEAE }\end{array}$ & & & & & & & & & & A & & & $P$ & 13181 \\
\hline Cecropia glaziovii Snethl. & & & & & & & $\mathrm{R}$ & & & & & RA & $P$ & 16403 \\
\hline $\begin{array}{l}\text { Cecropia pachystachya } \text { Trécul } \\
\text { VERBENACEAE }\end{array}$ & A & RA & RA & RA & A & A & RA & A & A & $\mathrm{R}$ & $\mathrm{RA}$ & & $\mathrm{P}$ & 15505 \\
\hline Aegiphila sellowiana Cham. & & & & RA & & $\mathrm{R}$ & & & & $\mathrm{R}$ & $\mathrm{R}$ & & $\mathrm{P}$ & 16944 \\
\hline Cytharexylum myrianthum Cham. & & & & & & & & $\mathrm{R}$ & & & & & $\mathrm{P}$ & 13223 \\
\hline
\end{tabular}

* Pereira (2003) 
Tabela 2 - Diversidade de espécies e densidade de indivíduos nas nascentes da bacia hidrográfica do ribeirão Santa Cruz, em Lavras, MG

Table 2 - Diversity of species and density of individuals in the springs of the Santa Cruz River watershed, Lavras, MG Brazil

\begin{tabular}{|c|c|c|c|c|}
\hline \multirow[t]{2}{*}{ Parâmetros da Vegetação } & \multicolumn{4}{|c|}{ Nascentes } \\
\hline & Perturbadas & Degradadas & Pontuais & Difusas \\
\hline $\mathrm{N}^{\circ}$ de espécies do estrato arbóreo & 87 & 72 & 110 & 38 \\
\hline $\mathrm{N}^{\circ}$ de espécies do estrato regenerativo & 159 & 125 & 189 & 87 \\
\hline $\mathrm{N}^{\circ}$ total de espécies & 176 & 143 & 204 & 96 \\
\hline Densidade média/ha no estrato arbóreo & 1.795 & 642 & 1.195 & 1.396 \\
\hline Densidade média/ha no estrato regenerativo & 18.020 & 8.321 & 15.015 & 14.310 \\
\hline
\end{tabular}

Nas nascentes pontuais foram amostradas 204 espécies, um número bem expressivo, quando comparado com as 96 espécies amostradas nas nascentes difusas (Tabela 2). Essa baixa diversidade de espécies nas nascentes difusas pode ser devida à maior disponibilidade de água no seu ambiente, o que deve estar exercendo uma seleção de espécies preferenciais a essa condição, visto que, conforme salientaram Oliveira-Filho et al. (1994ab) e Souza (2001), o regime de água é o principal fator ambiental associado à distribuição das espécies. Essa grande diferença entre o número de espécies não foi observada na densidade de indivíduos entre as categorias de nascentes pontuais e difusas (Tabela 2), confirmando que a umidade do ambiente foi mais importante para a seletividade das espécies, pouco influenciando a densidade da vegetação das nascentes estudadas.

As famílias que apresentaram o maior número de espécies foram: Myrtaceae (32), Melastomataceae (21), Lauraceae (17), Rubiaceae (16), Fabaceae Faboideae (11), Euphorbiaceae (11), Flacourtiaceae (7), Asteraceae (7) e Solanaceae (7)

As espécies que ocorreram em todas as categorias de nascentes em estudo (PP, PD, DP, DD), seguidas do número de nascentes em que foram amostradas, foram: Tapirira guianensis (11), Piper aduncum (11), Cecropia pachystachya (11), Lihtraea molleoides (10), Myrsine umbellata (10), Dendropanax cuneatus (9); Vernonanthura diffusa (9), Machaerium nictitans (9), Casearia sylvestris (9), Casearia decandra (8), Talauma ovata (8), Erytroxylum decidum (7), Nectandra nitidula (7), Zanthoxylum rhoifolium (7), Hyeronima ferruginea (5), Psychotria sessilis (5) e Miconia chamissois (4). Essas 17 espécies somam apenas 7,59\% das já identificadas e, no entanto, totalizaram $45,35 \%$ dos indivíduos, podendo ser consideradas as espécies em estudo de maior adaptabilidade ao ambiente das nascentes, em razão da sua alta frequiência e abundância. De forma oposta, 111 espécies (52\%) identificadas nas nascentes ocorreram apenas em uma das categorias estudadas: PP (56), DP (34), DD (11), PD (10).

Dentre as espécies amostradas, 103 ocorreram tanto no estrato arbóreo quanto no regenerativo. As categorias de nascentes perturbadas apresentaram 59 espécies amostradas, tanto no estrato arbóreo (A) quanto no regenerativo $(\mathrm{R})$, numa mesma nascente, enquanto as categorias das nascentes degradadas apresentaram 48 espécies. As nascentes perturbadas apresentaram, ainda, maior proporção de espécies presentes nos estratos arbóreo e regenerativo (105) que as nascentes degradadas (70) (Tabela 1), podendo-se inferir que estas exibiram maior proporção de árvores porta-sementes. O grande número de espécies presentes no estrato regenerativo que não estão no estrato arbóreo (106) indica que está ocorrendo o ingresso de novas espécies na área por meio da dispersão natural.

No que concerne aos grupos ecológicos, 30 espécies foram classificadas como pioneiras, 92 como clímax exigentes de luz e 64 como clímax tolerantes à sombra. As demais espécies amostradas nas nascentes não tiveram sua classificação encontrada na literatura. Nas nascentes degradadas foram registradas 19,70 e 27 espécies pioneiras, clímax exigentes de luz e clímax tolerantes à sombra, respectivamente. A predominância das espécies clímax exigentes de luz (70) verificada nas nascentes degradadas indica que elas se encontram em estádio sucessional médio (BRASIL, 1993). Já nas nascentes perturbadas foram registradas 27,63 e 61 espécies pioneiras, clímax exigentes em luz e clímax tolerantes à sombra, respectivamente. Verificou-se presença maior de espécies clímax tolerantes à sombra, assim como efeito da menor intensidade da fragmentação, 
em comparação com as nascentes degradadas, indicando que as nascentes perturbadas se encontravam em estádio sucessional mais avançado. As nascentes degradadas se achavam mais fragmentadas e antropizadas que as perturbadas, estando sob maior incidência dos raios solares, os quais fornecem condições favoráveis ao maior estabelecimento de espécies clímax exigentes de luz nessas nascentes.

A diferenciação do número de espécies nos distintos grupos ecológicos presentes nas duas categorias de nascentes permitiu inferir que, apesar de subjetiva, a classificação quanto ao estado de conservação dada das nascentes no campo foi correta.

\section{Similaridade florística entre os fragmentos no entorno das nascentes}

A DCA no estrato regenerativo (Figura 2) mostrou tendência de separação das nascentes em quatro grupos distintos, os quais vão ao encontro da classificação das nascentes nas respectivas categorias. O primeiro eixo de ordenação separou as nascentes degradadas das perturbadas, ressalvando-se a nascente PP2, que se encontrava no lado das nascentes degradadas. Essa nascente considerada perturbada apresentava-se com a presença assídua do gado, que leva a um grau maior de perturbação do estrato regenerativo, proporcionando maior similaridade com as nascentes degradadas. $\mathrm{O}$ segundo eixo separou as nascentes pontuais das difusas, ressalvando-se a nascente PD2.

\section{Diversidade florística}

O número de espécies quantificado em cada uma das quatro categorias variou bastante (Tabela 3 ). As categorias das nascentes pontuais degradadas e perturbadas apresentaram, respectivamente, 126 e 160 espécies, valores bastante superiores aos encontrados nas categorias das nascentes difusas degradadas e perturbadas, nas quais foram registradas 49 e 70 espécies, respectivamente. Tal fato leva aos maiores valores do índice de diversidade de Shannon-Weaver encontrado nas nascentes pontuais.

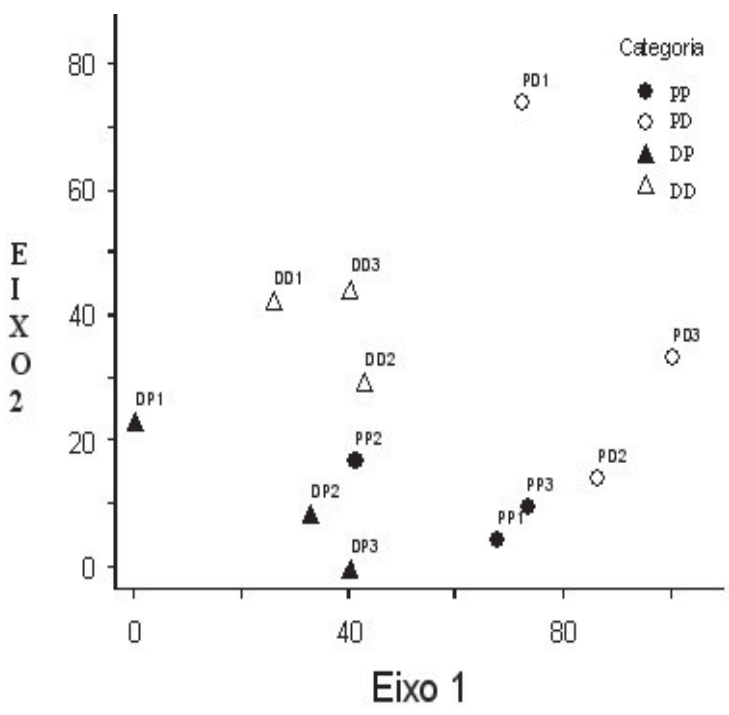

Figura 2 - Diagrama de ordenação da análise de correspondência retificada (DCA) da composição da flora do estrato regenerativo dos 12 fragmentos no entorno das nascentes da bacia hidrográfica do ribeirão Santa Cruz, em Lavras, MG.

Figure 2 - Ordination diagram yielded by detrended correspondence analysis (DCA) of species composition in the regenerative stratum of twelve forest fragments in the springs of the Santa Cruz River watershed, Lavras, $M G$ - Brazil.

Tabela 3 - Parâmetros quantitativos da vegetação das categorias de nascentes em conjunto e em separado: degradada difusa (DD), degradada pontual (DP), perturbada difusa (PD) e perturbada pontual (PP). $\mathbf{A}=$ área amostrada, $\mathbf{N}=$ número de indivíduos amostrados, DAT = densidade absoluta total, $\mathbf{E}=$ número de espécies amostradas, $\mathbf{F}=$ número de famílias amostradas, $\mathbf{H}^{\prime}=$ índice de diversidade de Shannon-Weaver $\left(\mathrm{H}^{\prime}\right)$ e $\mathbf{J}$ ' = índice de equabilidade de Pielou (J')

Table 3 - Quantitative parameters of the spring vegetation categories as a group or separated: diffuse degraded (DD), punctual degraded $(D P)$, diffuse disturbed $(P D)$ and punctual disturbed $(P P) . \boldsymbol{A}=$ sampled area, $\boldsymbol{N}=$ number of sampled individuals, $\boldsymbol{D A T}=$ total absolute density, $\boldsymbol{E}=$ number of sampled species, $\boldsymbol{F}=$ number of sampled families, $\boldsymbol{H}^{\prime}=$ Shannon-Weaver diversity index and $\boldsymbol{J}^{\prime}=$ Pielou evenness index

\begin{tabular}{lcrrrrr}
\hline Categoria da Nascente & A (ha) & N & DAT & E & F & H' \\
\hline Todas as categorias & 1,435 & 6851 & 4774 & 224 & 54 & 3,889 \\
DD & 0,304 & 502 & 1651 & 49 & 24 & 2,972 \\
DP & 0,339 & 1360 & 4012 & 126 & 42 & 0,764 \\
PD & 0,297 & 2138 & 7209 & 70 & 30 & 0,733 \\
PP & 0,495 & 2851 & 5760 & 160 & 46 & 2,636 \\
\hline
\end{tabular}


Os valores dos índices de diversidade de ShannonWeaver (H') e de equabilidade de Pielou (J') calculados para as 12 nascentes em conjunto foram, respectivamente, de 3,889 e 0,719 (Tabela3). Apesar de esses valores terem sido obtidos com as espécies do estrato arbóreo em conjunto com a regeneração, eles foram inferiores aos verificados no estrato arbóreo de fragmentos de mata ciliar da região estudados por Silva (2002), Souza (2001), Van den Berg (1995) e Oliveira-Filho et al. (1994a), os quais apresentaram, com relação ao índice de diversidade de Shannon-Weaver, valores de 4,148; 4,258; 3,924; e 4,204, respectivamente, e quanto ao índice de equabilidade de Pielou, valores de 0,868; 0,862; 0,793; e 0,880, respectivamente. Esses menores valores encontrados nas nascentes amostradas podem estar relacionados com as perturbações relatadas por Pinto (2003), que foram: menor tamanho dos fragmentos amostrados, estando estes sujeitos ao efeito borda da fragmentação, coleta seletiva de espécies de valor econômico e, principalmente, desmatamento para aumento da área agrícola e pastoril.

Quanto à equabilidade de Pielou (J'), as nascentes PD apresentaram o mais baixo valor $(62,1 \%)$, contrastando com os valores das demais categorias, que apresentaram variações pouco pronunciadas entre si. $\mathrm{O}$ baixo valor do índice de equabilidade de Pielou encontrado na categoria das nascentes PD permitiu inferir que há dominância ecológica mais pronunciada de algumas espécies que, juntas, predominam na comunidade dessa categoria, ou seja, maior concentração de indivíduos de espécies dominantes. Fato que pode justificar essa afirmativa é a ocorrência de alta densidade de poucas espécies: Hedyosmum brasiliense, Myrsine umbellata e Talauma ovata, com 7.328, 2.125 e 1.984 indivíduos por hectare no estrato regenerativo e 256,384 e 545 indivíduos por hectare no estrato arbóreo, respectivamente. $\mathrm{O}$ fator condicionante da presença dessas espécies é a água (LOBO e JOLY, 2001), elemento abundante nas nascentes difusas. Além disso, Hedyosmum brasiliense e Myrsine umbellata são espécies clímax exigentes de luz, enquanto Talauma ovata é uma espécie clímax tolerante à sombra (PEREIRA, 2003), ocorrendo em ambientes com menor interferência antrópica, como ocorre nas nascentes perturbadas, em comparação com as nascentes degradadas.

\section{Parâmetros fitossociológicos}

Os cálculos dos parâmetros fitossociológicos de interesse silvicultural são apresentados na Tabela 4.

Tabela 4 - Relação das espécies do estrato arbóreo e regenerativo amostradas em pelo menos três nascentes e nas quatro categorias de nascentes: $\mathbf{D D}=$ degradada difusa, $\mathbf{D P}=$ degradada pontual, $\mathbf{P D}=$ perturbada difusa e $\mathbf{P P}=$ perturbada pontual da bacia hidrográfica do ribeirão Santa Cruz, em Lavras, MG, com seus parâmetros fitossociológicos: DA = densidade absoluta e FA = freqüência absoluta. Espécies ordenadas em ordem alfabética

Table 4 - List of arboreal and regenerative stratum species sampled in at least three headwaters and in the four headwater categories: $\boldsymbol{D D}=$ diffuse degraded, $\boldsymbol{D P}=$ punctual degraded, $\boldsymbol{P D}=$ diffuse disturbed and $\boldsymbol{P P}=$ punctual disturbed of the Santa Cruz River watershed, Lavras, MG Brazil, with their phytosociological parameters: $\boldsymbol{D A}=$ absolute density and $\boldsymbol{F A}=$ absolute frequency. Species ordered in alphabetical order

\begin{tabular}{|c|c|c|c|c|c|c|c|c|c|c|c|c|c|c|c|c|}
\hline \multirow{3}{*}{ ESPÉCIES } & \multicolumn{8}{|c|}{ Estrato Arbóreo } & \multicolumn{8}{|c|}{ Estrato Regenerativo } \\
\hline & \multicolumn{2}{|c|}{ DD } & \multicolumn{2}{|c|}{ DP } & \multicolumn{2}{|c|}{ PD } & \multicolumn{2}{|c|}{$\mathbf{P P}$} & \multicolumn{2}{|c|}{ DD } & \multicolumn{2}{|c|}{ DP } & \multicolumn{2}{|c|}{ PD } & \multicolumn{2}{|c|}{$\mathbf{P P}$} \\
\hline & DA & FA & DA & FA & DA & $\mathbf{F A}$ & DA & FA & DA & FA & DA & FA & DA & FA & DA & FA \\
\hline Acacia glomerosa & & & & & & & & & & & 430 & 30 & & & & \\
\hline Aegiphila sellowiana & & & & & & & & & & & 110 & 16 & & & 28 & 5,7 \\
\hline Aiouea costaricensis & & & & & & & & & & & 20 & 2 & 94 & 13 & 28 & 5,7 \\
\hline Alibertia concolor & & & 3 & 8,3 & & & 8 & 17 & & & 50 & 8 & & & 28 & 5,7 \\
\hline Bauhinia longifolia & & & & & & & & & & & 50 & 8 & 16 & 3,1 & 57 & 7,6 \\
\hline Blepharocalyx salicifolius & & & & & & & & & & & & & & & 75 & 5,7 \\
\hline Calophyllum brasiliense & & & & & & & & & & & & & 94 & 9,4 & 528 & 25 \\
\hline Calyptranthes clusiifolia & & & & & & & & & & & 20 & 4 & 2109 & 25 & 349 & 25 \\
\hline Campomanesia guazumifolia & & & & & & & & & & & & & & & 19 & 3,8 \\
\hline Casearia decandra & & & & & & & 6 & 17 & 68 & 5,4 & 270 & 26 & 47 & 6,3 & 236 & 25 \\
\hline Casearia sylvestris & & & 6 & 17 & & & 10 & 33 & 41 & 5,4 & 80 & 16 & 16 & 3,1 & 208 & 25 \\
\hline Cecropia glaziovii & & & & & 13 & 33 & 8 & 17 & & & & & & & & \\
\hline Cecropia pachystachya & 13 & 33 & 29 & 50 & 71 & 67 & 8 & 25 & 68 & 8,1 & 140 & 16 & 47 & 9,4 & 28 & 3,8 \\
\hline
\end{tabular}

R. Árvore, Viçosa-MG, v.29, n.5, p.775-793, 2005 
Estudo da vegetação como subsídios para propostas ...

Tabela 4 - Cont.

Table 4-Cont.

\begin{tabular}{|c|c|c|c|c|c|c|c|c|c|c|c|c|c|c|c|c|}
\hline \multirow{3}{*}{ ESPÉCIES } & \multicolumn{8}{|c|}{ Estrato Arbóreo } & \multicolumn{8}{|c|}{ Estrato Regenerativo } \\
\hline & \multicolumn{2}{|c|}{ DD } & \multicolumn{2}{|c|}{ DP } & \multicolumn{2}{|c|}{ PD } & \multicolumn{2}{|c|}{$\mathbf{P P}$} & \multicolumn{2}{|c|}{ DD } & \multicolumn{2}{|c|}{ DP } & \multicolumn{2}{|c|}{ PD } & \multicolumn{2}{|c|}{$\mathbf{P P}$} \\
\hline & DA & FA & DA & FA & DA & FA & DA & FA & DA & FA & DA & FA & DA & FA & DA & FA \\
\hline Cedrelafissilis & & & 3 & 8,3 & 3 & 11 & 4 & 8,3 & & & & & & & & \\
\hline Celtis iguanaea & & & 18 & 25 & & & 12 & 25 & & & 160 & 20 & & & 28 & 5,7 \\
\hline Cestrum laevigatum & & & & & & & & & & & 40 & 2 & 250 & 19 & 47 & 9,4 \\
\hline Chomelia sericea & & & 3 & 8,3 & & & 6 & 17 & & & & & & & & \\
\hline Chrysophyllum marginatum & & & & & & & 8 & 33 & & & 70 & 14 & 16 & 3,1 & 113 & 19 \\
\hline Citronella paniculata & & & & & & & & & & & & & & & 47 & 3,8 \\
\hline Copaifera langsdorffii & & & 35 & 33 & 3 & 11 & 36 & 42 & & & 460 & 34 & 125 & 16 & 538 & 45 \\
\hline Cordia trichotoma & & & 21 & 33 & 3 & 11 & & & & & 80 & 14 & & & & \\
\hline Croton urucurana & & & & & & & & & & & & & 63 & 6,3 & & \\
\hline Dendropanax cuneatus & & & 12 & 25 & 61 & 56 & 30 & 58 & 54 & 2,7 & 40 & 6 & 547 & 22 & 264 & 34 \\
\hline Erythroxylum ambiguum & & & & & & & & & & & 30 & 4 & & & 47 & 7,6 \\
\hline Erythroxylum deciduum & 3 & 11 & 3 & 8,3 & 3 & 11 & 2 & 8,3 & 41 & 8,1 & 50 & 8 & 16 & 3,1 & 104 & 17 \\
\hline Esenbeckia febrifuga & & & & & & & & & & & 10 & 2 & 16 & 3,1 & 47 & 7,6 \\
\hline Eugenia florida & & & 3 & 8,3 & & & 2 & 8,3 & & & & & 16 & 3,1 & 75 & 9,4 \\
\hline Ficus guaranitica & & & & & & & & & & & & & & & 47 & 7,6 \\
\hline Gochnatia paniculata & & & 3 & 8,3 & & & 16 & 33 & & & 30 & 6 & & & 113 & 13 \\
\hline Guarea kunthiana & & & & & & & & & & & & & 188 & 19 & 94 & 7,6 \\
\hline Guettarda uruguensis & & & & & & & & & & & 30 & 4 & & & & \\
\hline $\begin{array}{l}\text { Hedyosmum brasiliense } \\
\text { Hyeronima alchorneoides }\end{array}$ & & & 3 & 8,3 & 256 & 67 & $\begin{array}{c}28 \\
6\end{array}$ & $\begin{array}{l}17 \\
25\end{array}$ & & & & & 7328 & 72 & 292 & 19 \\
\hline Hyeronima ferruginea & 3 & 11 & 3 & 8,3 & 64 & 44 & 10 & 1,7 & & & & & 359 & 25 & 189 & 17 \\
\hline Ilex cerasifolia & 3 & 11 & & & & & 2 & 8,3 & & & & & & & 66 & 7,6 \\
\hline Inga striata & & & 6 & 17 & & & & & & & 20 & 4 & & & & \\
\hline Lacistema hasslerianum & & & & & & & & & 203 & 19 & 260 & 22 & & & 415 & 32 \\
\hline Lithraea molleoides & 30 & 11 & 21 & 33 & 37 & 22 & 162 & 75 & 351 & 19 & 210 & 16 & 63 & 9,4 & 519 & 32 \\
\hline Luehea divaricata & & & 32 & 42 & & & & & & & 150 & 20 & & & & \\
\hline Machaerium hirtum & & & 21 & 42 & & & 10 & 25 & & & 30 & 4 & & & 28 & 3,8 \\
\hline Machaerium nictitans & 3 & 11 & 9 & 17 & 3 & 11 & 22 & 25 & 14 & 2,7 & 90 & 14 & 16 & 9,4 & 47 & 7,6 \\
\hline Machaerium stipitatum & & & & & & & & & 41 & 8,1 & 30 & 4 & & & 9 & 1,9 \\
\hline Maclura tinctoria & & & 3 & 8,3 & & & 8 & 25 & & & & & & & & \\
\hline Miconia albicans & 3 & 11 & & & & & & & & & & & & & & \\
\hline Miconia argyrophylla & & & & & & & & & & & 10 & 2 & & & 28 & 3,8 \\
\hline Miconia chamissois & & & & & & & & & 27 & 2,7 & 60 & 6 & 1484 & +31 & 28 & 5,7 \\
\hline Miconia chartacea & & & & & & & & & & & & & & & 236 & 17 \\
\hline Miconia cyanocarpa & & & & & & & & & 338 & 22 & & & 63 & 9,4 & 236 & 3,8 \\
\hline Miconia latecrenata & & & & & & & & & & & 10 & 2 & 16 & 3,1 & 19 & 7,6 \\
\hline Miconia theaezans & & & & & & & & & & & & & 891 & 35 & 47 & 9,4 \\
\hline Mollinedia argyrogyna & & & 3 & 8,3 & & & 2 & 8,3 & & & & & & & & \\
\hline Myrcia tomentosa & & & 6 & 17 & & & & & 14 & 2,7 & 10 & 2 & & & 38 & 7,6 \\
\hline Myrcia velutina & & & & & & & 10 & 17 & 27 & 5,4 & 100 & 12 & & & 113 & 5,7 \\
\hline Myrcia venulosa & & & 3 & 8,3 & & & 8 & 17 & 14 & 2,7 & 30 & 4 & & & 1170 & 38 \\
\hline Myrsine umbellata & 56 & 22 & 3 & 8,3 & 384 & 89 & 51 & 33 & 500 & 27 & 100 & 10 & 2125 & 572 & 368 & 28 \\
\hline Nectandra nitidula & 13 & 11 & 171 & 42 & & & 30 & 33 & 1284 & 22 & 2950 & 38 & 31 & 6,3 & 1198 & 34 \\
\hline Nectandra oppositifolia & & & 6 & 17 & & & 4 & 17 & & & 10 & 2 & & & 38 & 7,6 \\
\hline Ocotea pulchella & & & 53 & 67 & & & 24 & 50 & & & 130 & 16 & 63 & 6,3 & 151 & 17 \\
\hline Pera glabrata & & & & & & & & & & & 30 & 6 & & & 198 & 13 \\
\hline Persea pyrifolia & & & & & 3 & 11 & 6 & 8,3 & 68 & 11 & 80 & 10 & 16 & 3,1 & 245 & 26 \\
\hline Pimenta pseudocaryophyllus & & & & & 3 & 11 & 105 & 58 & & & & & & & 1189 & 47 \\
\hline Piper aduncum & & & & & & & & & 270 & 35 & 650 & 32 & 47 & 6,3 & 1179 & 47 \\
\hline Piper caldense & & & & & & & & & & & & & 188 & 28 & & \\
\hline Piper mikanianum & & & & & & & & & 14 & 2,7 & 360 & 10 & 16 & 3,1 & & \\
\hline
\end{tabular}

Continua...

Continued... 
Tabela 4 - Cont

Table 4 - Cont

\begin{tabular}{|c|c|c|c|c|c|c|c|c|c|c|c|c|c|c|c|c|}
\hline \multirow{3}{*}{ ESPÉCIES } & \multicolumn{8}{|c|}{ Estrato Arbóreo } & \multicolumn{8}{|c|}{ Estrato Regenerativo } \\
\hline & \multicolumn{2}{|c|}{ DD } & \multicolumn{2}{|c|}{ DP } & \multicolumn{2}{|c|}{ PD } & \multicolumn{2}{|c|}{$\mathbf{P P}$} & \multicolumn{2}{|c|}{ DD } & \multicolumn{2}{|c|}{ DP } & \multicolumn{2}{|c|}{ PD } & \multicolumn{2}{|c|}{$\mathbf{P P}$} \\
\hline & DA & FA & DA & FA & DA & FA & DA & FA & DA & FA & DA & FA & DA & FA & DA & FA \\
\hline Piptadenia gonoacantha & & & 3 & 8,3 & & & 2 & 8,3 & & & & & & & & \\
\hline Platypodium elegans & & & 41 & 33 & 3 & 11 & 4 & 17 & & & 180 & 26 & & & & \\
\hline Protium heptaphyllum & & & 133 & 42 & 162 & 67 & 154 & 58 & & & 470 & 34 & 500 & 25 & 2726 & 40 \\
\hline Protium spruceanum & & & & & & & & & & & & & 156 & 6,3 & & \\
\hline Psidium cinereum & & & 6 & 8,3 & 10 & 11 & & & 14 & 2,7 & 10 & 2 & 16 & 3,1 & & \\
\hline Psidium rufum & & & & & & & & & & & & & & & 113 & 13 \\
\hline Psychotria carthagenensis & & & & & & & & & & & & & & & 19 & 3,8 \\
\hline Psychotria sessilis & & & 6 & 17 & 7 & 11 & & & 14 & 2,7 & 20 & 4 & 47 & 3,1 & 340 & 17 \\
\hline Rollinia laurifolia & & & & & & & & & & & 30 & 6 & & & 57 & 9,4 \\
\hline Rollinia sylvatica & & & 6 & 17 & & & 4 & 17 & & & & & & & & \\
\hline Rudgea viburnoides & & & & & 3 & 11 & 2 & 8,3 & & & & & & & & \\
\hline Sapium glandulosum & & & & & 7 & 11 & 2 & 8,3 & & & & & & & & \\
\hline Schinus terebinthifolius & 7 & 11 & & & 17 & 44 & 2 & 8,3 & 14 & 2,7 & & & 94 & 9,4 & 19 & 3,8 \\
\hline Siparuna cujabana & & & 3 & 8,3 & & & 2 & 8,3 & & & & & 16 & 3,1 & 189 & 19 \\
\hline Siparuna guianensis & & & 3 & 8,3 & & & 4 & 8,3 & & & 40 & 6 & 63 & 9,4 & 104 & 13 \\
\hline Siphoneugena densiflora & & & & & & & & & 14 & 2,7 & 40 & 6 & & 19 & 3,8 & \\
\hline Solanum lycocarpum & & & & & & & & & 14 & 2,7 & 90 & 8 & & & 9 & 1,9 \\
\hline Tabebuia serratifolia & & & & & & & & & 27 & 5,4 & 50 & 8 & & & 9 & 1,9 \\
\hline Talauma ovata & 33 & 11 & 6 & 8,3 & 545 & 100 & 176 & 58 & & & 20 & 2 & 1984 & 56 & 783 & 28 \\
\hline Tapirira guianensis & 86 & 44 & 74 & 50 & 774 & 100 & 194 & 83 & 419 & 24 & 210 & 22 & 844 & 44 & 1123 & 47 \\
\hline Tapirira obtusa & & & 9 & 25 & & & 10 & 25 & & & & & & & & \\
\hline Tibouchina candolleana & 69 & 44 & & & 7 & 11 & 2 & 8,3 & 162 & 16 & & & 47 & 6,3 & 9 & 1,9 \\
\hline Tibouchina stenocarpa & & & & & & & & & 392 & 27 & 120 & 14 & & & 38 & 3,8 \\
\hline Vernonanthura diffusa & & & & & & & & & 54 & 11 & 50 & 10 & 16 & 3,1 & 179 & 21 \\
\hline Zanthoxylum rhoifolium & & & 6 & 17 & 3 & 11 & & & 54 & 5,4 & 40 & 8 & & & 57 & 9,4 \\
\hline
\end{tabular}

Tapirira guianensis, reconhecida como generalista por "habitats", destaca-se pela alta densidade e frequiência no estrato arbóreo e regenerativo de todas as categorias das nascentes (OLIVEIRA-FILHO e RATTER, 2001). Tal fato pode ser justificado pela sua presença em $54,3 \%$ dos 43 fragmentos de floresta ciliar do Brasil extraamazônico analisados por Rodrigues e Nave (2001).

Talauma ovata destaca-se pela alta densidade e freqüência nos estratos arbóreo e regenerativo das nascentes perturbadas pontuais e difusas. É típica de matas de brejo e de locais propensos à inundação periódica de longa duração (LOBO e JOLY, 2001), sendo importante para a recuperação de nascentes perturbadas pontuais e difusas, quando plantada próximo do curso e do olho d'água, ou seja, em áreas sob a influência direta do lençol freático.

Quanto à densidade no estrato regenerativo, Copaifera langsdorffii é importante na recuperação de nascentes pontuais (DP e PP), no entanto é generalista por "habitat" (OLIVEIRA-FILHO e RATTER, 2001), podendo ser plantada em áreas sujeitas ao alagamento (LOBO e JOLY, 2001); já Myrsine umbellata é importante na recuperação de nascentes difusas (DD e PD), nas quais a água é fator condicionante para presença dessa espécie. As espécies abundantes das nascentes PD podem ser consideradas como as mais especialistas, pelo fato de $60 \%$ delas (Hedyosmum brasiliense, Calyptranthes clusiifolia, Dendropanax cuneatus, Hyeronima ferruginea, Miconia theaezans, Miconia chamissois) serem abundantes somente nessa categoria de nascente.

\section{Propostas para recuperação das nascentes}

Deve-se dar prioridade às nascentes degradadas pouco vegetadas e mais suscetíveis aos processos erosivos. Áreas de nascentes com solo compactado e com estrato regenerativo comprometido pela presença do gado também devem ser consideradas. O processo de recuperação deve iniciar nas partes mais altas da bacia, de forma que, com o estabelecimento da vegetação, esta contribua para o processo de recuperação das

R. Árvore, Viçosa-MG, v.29, n.5, p.775-793, 2005 
áreas de mata ciliar a jusante a partir da dispersão de seus propágulos pela fauna (PIÑA-RODRIGUES et al., 1990) e pelo leito dos cursos d'água (PINTO et al., 2004b), dando continuidade ou, mesmo, acelerando o processo de sucessão (OLIVEIRA-FILHO, 1994).

Para a recuperação das APPs no entorno das nascentes perturbadas e degradadas da Bacia Hidrográfica do Ribeirão Santa Cruz, recomenda-se, na maioria dos casos, o plantio misto com o máximo de diversidade de espécies nativas, seguindo o modelo de sucessão secundária. Pelos resultados obtidos em experimentos na região do Alto Rio Grande (PEREIRA et al., 1999; BOTELHO et al., 1996; BOTELHO et al., 1995; DAVIDE e FARIA, 1994; DAVIDE et al., 1993ab;), recomenda-se o plantio em quincôncio, com o uso simultâneo de $50 \%$ de espécies pioneiras, $30 \%$ de espécies clímax exigentes de luz e $20 \%$ de espécies clímax tolerantes à sombra.

Dependendo do grau de perturbação da nascente e, considerando as condições químicas, físicas e biológicas do solo, a presença de árvores fornecedoras de sementes e o estágio do estrato regenerativo, poderá ser utilizado o plantio de enriquecimento (GANDOLFI e RODRIGUES, 1996) ou somente a regeneração natural (BOTELHO et al., 2001).

Independentemente do tipo e do estado de conservação da nascente a ser recuperada, o primeiro passo a ser tomado é o isolamento da área num raio de $50 \mathrm{~m}$ da nascente, para impedir a invasão por animais domésticos, evitando, principalmente, a compactação do solo pelo pisoteio e o comprometimento do estrato regenerativo da área. Como a maioria das nascentes da bacia hidrográfica está circundada por cultura agrícola ou pastagem, o segundo passo a ser dado é o abandono dessas atividades dentro da área a ser restaurada, para que não exerçam competição com as espécies arbóreas plantadas ou regeneradas naturalmente.

A indicação das espécies para utilização nos processos de recuperação das nascentes foi feita com base nos dados obtidos no estrato regenerativo, considerando-se que a presença de uma espécie neste estrato, em determinado ambiente, indica sua adaptação às condições locais. A partir da observação de similaridade florística do estrato regenerativo entre as nascentes da mesma categoria (Figura 2), foi possível agrupar as espécies a serem indicadas nas diferentes situações.
As espécies mais abundantes e freqüentes do estrato regenerativo (Tabela 4) foram separadas em quatro grupos, de acordo com o estado de conservação das nascentes e das condições do ambiente onde se encontraram, dando origem à Tabela 5 .

As espécies a serem plantadas deverão ser selecionadas dentre as listadas na Tabela 5, de acordo com a disponibilidade de mudas ou sementes. Se possível, deve-se dar preferência às espécies frutíferas, para promover a atração de animais silvestres (ANDRADE, 2003), que são importantes no processo de dispersão, acelerando a dinâmica de sucessão (PIÑA-RODRIGUES et al., 1990).

Cerca de $70 \%$ das espécies listadas na Tabela 5 encontram-se entre as espécies mais abundantes nas matas ciliares da bacia do Alto e Médio Rio Grande (OLIVEIRA-FILHO et al., 1995), podendo inferir que há semelhança florística entre essas comunidades.

Nas nascentes perturbadas pontuais e difusas, onde a intervenção não foi tão acentuada para prejudicar sua resiliência, o simples isolamento dessas áreas pode ser efetivo, tendo em vista que, nesses casos, normalmente existe vegetação arbórea em parte da área, o que possibilitará o retorno do processo de regeneração natural das espécies. Nas nascentes perturbadas, as quais tiveram sua resiliência afetada por alterações mais drásticas, recomenda-se o plantio em toda a área livre de vegetação ou o enriquecimento, caso exista regeneração natural em andamento. Se a área a ser restaurada encontra-se sobre solos bem drenados, sem influência do curso d'água, recomendam-se as espécies do grupo 1; se a área estiver próxima ao curso d'água, sujeita à inundação periódica ou sob influência do lençol freático em áreas brejosas, recomendam-se espécies tolerantes a solos úmidos, encontradas no grupo 2 .

Nas nascentes degradadas pontuais e difusas, em razão de níveis intensos de alteração, sua resiliência encontra-se bastante afetada, sendo necessária uma minuciosa intervenção antrópica para que sejam superados os impedimentos existentes à regeneração natural. Nas nascentes onde a degradação favoreceu o desenvolvimento de populações dominantes de bambus e lianas, espécies típicas da mata ciliar (RODRIGUES e GANDOLFI, 2001), deve-se realizar o controle do número de indivíduos dessas populações para reduzir a competição com a regeneração das espécies arbóreas, possibilitando o avanço sucessional.

R. Árvore, Viçosa-MG, v.29, n.5, p.775-793, 2005 
Tabela 5 - Relação das espécies com potencial para utilização na recuperação das nascentes da bacia hidrográfica do ribeirão Santa Cruz, em Lavras, MG, separadas em grupos: 1 = espécies indicadas para solos bem drenados de nascentes perturbadas, 2 =espécies indicadas para solos úmidos ou encharcados de nascentes perturbadas, $3=$ espécies indicadas para solos bem drenados de nascentes degradadas e 4 = espécies indicadas para solos úmidos ou encharcados de nascentes degradadas

Table 5 - List of species with potential use in the recovery of springs of the Santa Cruz stream River watershed, Lavras, $M G$-Brazil, separated in groups: 1 = suitable species for well drained soils of disturbed springs, $2=$ suitable species for humid or waterlogged soils of disturbed springs, $3=$ suitable species for well drained soils of degraded springs, 4 = suitable species for humid or waterlogged soils of degraded springs

\begin{tabular}{|c|c|c|}
\hline Espécies & Nome Vernacular & Grupos para Recomposição \\
\hline \multicolumn{3}{|c|}{ Pioneiras } \\
\hline$\overline{\text { Aegiphila sellowiana }}{ }^{+*}$ & Pau-de-tamanco & 3 \\
\hline Casearia sylvestris $+*$ & Erva- largato & 1,3 \\
\hline Cecropia pachystachya ${ }^{+}$ & Embaúba & $1,3,4$ \\
\hline Celtis iguanaea & Esporão-de-galo & 3 \\
\hline Croton urucurana ${ }^{+}$ & Sangra-d'água & 2 \\
\hline Gochnatia paniculata & Cambarazinho & 1,3 \\
\hline Lithraea molleoides ${ }^{+} *$ & Aroeira-brava & $1,3,4$ \\
\hline Piper aduncum & Jaborandi & $1,3,4$ \\
\hline Psychotria sessilis ${ }^{+}$ & Folha-miúda & $1,2,3,4$ \\
\hline Schinus terebinthifolius $*$ & Aroeira-vermelha & 2 \\
\hline Tapirira guianensis ${ }^{+}$ & Pombeiro & $1,2,3,4$ \\
\hline Vernonanthura diffusa ${ }^{+}$ & Vassourão-preto & 1,4 \\
\hline \multicolumn{3}{|c|}{ Clímax Exigentes em Luz } \\
\hline Acacia glomerosa $^{+}$ & Espinheiro & 3 \\
\hline Chrysophyllum marginatum ${ }^{+}$ & Guatambu-de-leite & 1,3 \\
\hline Cordia trichotoma & Louro-pardo, violeiro & 3 \\
\hline Hedyosmum brasiliense & Espiradeira-da-mata & 2 \\
\hline Hyeronima ferruginea $^{+}$ & Vermelhão-do-mato & 2 \\
\hline Luehea divaricata $^{+}$ & Açoita-cavalo & 3 \\
\hline Machaerium nictitans ${ }^{+}$ & Bico-de-pato & $1,2,3$ \\
\hline \multicolumn{3}{|c|}{ Clímax Exigentes em Luz } \\
\hline Machaerium stipitatum $^{+}$ & Monjolinho & 4 \\
\hline Myrcia venulosa ${ }^{+}$ & Guará-mirim-do-campo & 1,4 \\
\hline Myrsine umbellata $^{+}$ & Pororoca-branca & 2,4 \\
\hline Nectandra nitidula ${ }^{+}$ & Canela-amarela & $1,3,4$ \\
\hline Ocotea pulchella $+*$ & Canela-preta & 1,3 \\
\hline Persea pyrifolia ${ }^{+}$ & Massaranduba & $1,3,4$ \\
\hline Pimenta pseudocaryophyllus & Cravo-do-mato & 1 \\
\hline Platypodium elegans + & Jacarandá-branco & 3 \\
\hline Protium heptaphyllum + & Breu-vermelho & $1,2,3$ \\
\hline Tibouchina candolleana & Quaresmeira, manacá & 4 \\
\hline Tibouchina stenocarpa & Quaresma & 3,4 \\
\hline Zanthoxylum rhoifolium ${ }^{+}$ & Mamica-de-porca & 4 \\
\hline \multicolumn{3}{|c|}{ Clímax Tolerante à Sombra } \\
\hline$\overline{\text { Aiouea costaricensis }}$ & - & 2 \\
\hline Calophyllum brasiliense ${ }^{+}$ & Guanandi & 2 \\
\hline Calyptranthes clusiifolia ${ }^{+}$ & Orelha-de-burro & 1,2 \\
\hline Casearia decandra $+*$ & Espeto & 1,3 \\
\hline Cestrum laevigatum & Dama-da-noite & 1,2 \\
\hline Copaifera langsdorffii $+*$ & Pau-d'óleo, copaíba & $1,2,3$ \\
\hline Dendropanax cuneatus $+*$ & Maria-mole & 1,2 \\
\hline Erythroxylum deciduum & Fruta-de-juriti & $2,3,4$ \\
\hline Esenbeckia febrifuga & Mamoninha & 1 \\
\hline Eugenia florida $+*$ & Pimenteira & 1 \\
\hline Guarea kunthiana $+*$ & Peloteira & 1,2 \\
\hline Lacistema hasslerianum $^{+}$ & Cafeeiro-do-mato & 1,3 \\
\hline Nectandra oppositifolia ${ }^{+}$ & Canela-ferrugem & 1,3 \\
\hline Siparuna guianensis ${ }^{+}$ & Negramina & $1,2,3$ \\
\hline Siphoneugena densiflora ${ }^{+}$ & Guaramirim & $1,3,4$ \\
\hline Tabebuia serratifolia ${ }^{+}$ & Ipê-amarelo & 1 \\
\hline Talauma ovata ${ }^{+}$ & Pinha-do-brejo & 2 \\
\hline
\end{tabular}

+Espécies abundantes nas matas ciliares na bacia do Alto e Médio Rio Grande (OLIVEIRA-FILHO et al., 1995).

* Espécies zoocóricas (CARMO e MORELLATO, 2001).

R. Árvore, Viçosa-MG, v.29, n.5, p.775-793, 2005 
Apenas esses tratamentos não são suficientes para a efetiva recuperação dessas áreas que, muitas vezes, encontram-se muito pouco vegetadas, havendo a necessidade de plantio para reintrodução das espécies e suprir a falta de árvores-matriz fornecedoras de sementes para a regeneração natural. Se a área a ser restaurada encontra-se sobre solos bem drenados, sem influência do lençol freático e do curso d'água, recomendamse as espécies do grupo 3, na proporção de $70 \%$, e do grupo 1 , na proporção de $30 \%$; se a área estiver próxima ao curso d'água, sujeita à inundação periódica ou sob a influência do lençol freático em áreas brejosas, recomendam-se espécies do grupo 4, que são tolerantes a solos úmidos. Essa proporção diferenciada entre os grupos de espécies visa à aceleração da dinâmica da recuperação do fragmento pela introdução de espécies presentes em fragmentos mais conservados.

A definição do espaçamento pode ter como base a densidade média do estrato arbóreo encontrada nas 12 nascentes em conjunto, ou seja, 1.279 indivíduos/ ha, resultando num espaçamento de aproximadamente 3,0 x 2,6 m. Entretanto, haja vista a inexistência de estudos sobre a densidade de plantio em nascentes e um possível efeito sobre a sua vazão, dada a proximidade do lençol freático, sugere-se, para o espaçamento inicial de plantio, o uso de densidades menores do que a encontrada, independentemente das condições de perturbação.

Devido à localização, a mecanização deverá ser evitada, só sendo utilizada em casos de necessidade de descompactação do solo. Na maioria dos casos, portanto, recomenda-se o coveamento. Os tratos culturais podem limitar-se ao coroamento, tanto das mudas já estabelecidas como das mudas plantadas no sistema de enriquecimento, e devem ser mantidos até o fechamento das copas, quando a competição das espécies invasoras é menor. O controle de formigas e cupins deve ser mantido por até dois anos após o plantio.

\section{CONCLUSÃO}

A vegetação do estrato arbóreo apresentou maior diversidade nas nascentes perturbadas em relação às degradadas, assim como nas nascentes pontuais em relação às difusas.

A similaridade florística do estrato regenerativo entre as nascentes de mesma categoria: perturbada pontual (PP), perturbada difusa (PD), degradada pontual (DP) e degradada difusa (DD) permitiu inferir que se devem utilizar espécies preferenciais em cada estado de conservação (perturbado ou degradado) e condições do ambiente (solo úmido ou bem drenado), nos programas de recuperação das áreas de preservação permanente das nascentes da Bacia Hidrográfica do Ribeirão Santa Cruz, em Lavras, MG.

\section{REFERÊNCIAS BIBLIOGRÁFICAS}

ANDRADE, M. A. Arvores zoocóricas como núcleos de atração de avifauna e dispersão de sementes. 2003. $91 \mathrm{f}$.

Dissertação (Mestrado em Engenharia Florestal) Universidade Federal de Lavras, Lavras, 2003.

BOTELHO, S. A.; DAVIDE, A. C. Métodos silviculturais para recuperação de nascentes e recomposição de matas ciliares. In: SIMPÓSIO NACIONAL SOBRE RECUPERAÇÃO DE ÁREAS DEGRADADAS, 5., 2002, Belo Horizonte.

Anais... Belo Horizonte: 2002. p. 123-145.

BOTELHO, S. A.; DAVIDE, A. C.; FARIA, J. M. R. Desenvolvimento inicial de seis espécies florestais nativas em dois sítios, na região sul de Minas Gerais. Cerne, v. 2, n. 1, p. 43-52, 1996.

BOTELHO, S. A. et al. Implantação de florestas de proteção. Lavras: Universidade Federal de Lavras/FAEPE, 2001. 81p.

BOTELHO, S. A. et al. Implantação de Mata Ciliar. Belo Horizonte: CEMIG/UFLA/FAEPE, 1995. 36 p.

BRASIL. Ministério da Agricultura e Reforma Agrária. Normais climatológicas 19611990. Brasília: 1992. 84 p.

BRASIL. Congresso. Senado. Resolução n. ${ }^{\text {' 303, }}$ de 20 de mar de 2002. Dispõe sobre parâmetros, definições e limites de áreas de Preservação Permanente. Disponível em: <http:// www.mma.gov.br/conama/>. Acesso em: 07 set. 2002a.

BRASIL. Lei n. 4. 771, 15 set. 1965. Institui o novo Código Florestal. Disponível em: <http:// www.planalto.gov.br/CCIVIL/Leis/L4771.htm>. Acesso em: 07 set. 2002b.

BROWER, J. E.; ZAR, J. H. Field and laboratory methods for general ecology. Dubuque: W. M. C. Brow, 1984. 226 p.

R. Árvore, Viçosa-MG, v.29, n.5, p.775-793, 2005 
CARMO, M. R. B.; MORELLATO, L. P. C. Fenologia de árvores e arbustos das matas ciliares da bacia do Rio Tibagi, Estado do Paraná, Brasil. In: RODRIGUES, R. R.; LEITÃO FILHO, H. Matas ciliares: conservação e recuperação. 2. ed. São Paulo: Universidade de São Paulo/ Fapesp, 2001, p. 125-141.

CARVALHO, D. A. et al. Estudos florísticos e fitossociológicos em remanescentes de Florestas Ripárias do Alto São Francisco e Bacia do Rio Doce - MG. Lavras: Universidade Federal de Lavras/ CEMIG, 1999. 39 p.

CAUSTON, D. R. An introduction to vegetation analysis, principles and interpretation. London: Unwin Hyman, 1988. 342p.

BRASIL. Ministério da Agricultura. Resolução CONAMA, n.10, de 01 de outubro de 1993. Brasília: 1993.

DAVIDE, A. C.; FARIA, J. M. R. Recomposição de matas ciliares em dois sítios às margens da represa de Camargos/Itutinga, MG. In: SIMPÓSIO INTERNACIONAL DE ESTUDOS AMBIENTAIS SOBRE ECOSSISTEMAS FLORESTAIS, 3. FOREST'94, 1994, Porto Alegre. Anais. . . Porto Alegre: 1994. p. 46-47.

DAVIDE, A. C.; SCOLFORO, J. R. S.; FARIA, J. M. R. Adaptação de 12 espécies florestais em área de empréstimo. In: CONGRESSO FLORESTAL PANAMERICANO, 1.; CONGRESSO FLORESTAL BRASILEIRO, 7., 1993, Curutiba. Anais. . . Curitiba: SBS/SBEF, 1993a. p. 754.

DAVIDE, A. C.; SCOLFORO, J. R. S.; FARIA, J. M. R. Comportamento silvicultural de 7 espécies florestais em área de empréstimo. In: CONGRESSO FLORESTAL PANAMERICANO, 1.; CONGRESSO FLORESTAL BRASILEIRO, 7., 1993, Curitiba. Anais. . Curitiba: SBS/SBEF, 1993b. p. 756.

GANDOLFI, S.; RODRIGUES, R. R.

Recomposição de florestas nativas: algumas perspectivas metodológicas para o estado de São Paulo. Curitiba: UNFP, 1996. p. 83-100. (3º curso de Recuperação de Áreas Degradadas).

R. Árvore, Viçosa-MG, v.29, n.5, p.775-793, 2005
LIMA, W. P. A função hidrológica da mata ciliar. In: SIMPÓSIO SOBRE MATA CILIAR, 1989, Campinas. Anais... Campinas: Fundação Cargil, 1989. p. 25-42.

LOBO, P. C.; JOLY, C. A. Aspectos ecofisiológicos da vegetação de mata ciliar do sudeste do Brasil. In: RODRIGUES, R. R.; LEITÃO FILHO, $H$. Matas ciliares: conservação e recuperação. 2. ed. São Paulo: Universidade de São Paulo/ Fapesp, 2001. p. 143-158.

McCUNE, B.; MEFFORD, M. J. PC_ORD version 4. 0 , multivariate analysis of ecolofical data, Users guide. Glaneden Beach, Oregon: MjM Sofware Design, 1999. 237 p.

MUELLER-DUMBOIS, D.; ELLENBERG, M. Aims and methods of vegetation ecology. New york: John Wiley \& Sons, 1974. 547 p.

OLIVEIRA-FILHO, A. T.; RATTER, J. A. Padrões florísticos das matas ciliares da região do cerrado e a a evolução das paisagens do Brasil Central durante o quartenário tardio. In: RODRIGUES, R. R.; LEITÃ̃ FILHO, H. Matas ciliares: conservação e recuperação. 2. ed. São Paulo: Universidade de São Paulo/ Fapesp, 2001. p. 73-89.

OLIVEIRA-FILHO, A. T. et al. Estudos florísticos e fitossociológicos em remanescentes de matas ciliares do Alto e Médio Rio Grande. Belo Horizonte: CEMIG, 1995. 27 p.

OLIVEIRA-FILHO, A. T. Estudos ecológicos da vegetação como subsídios para programas de revegetação com espécies nativas: uma proposta metodológica. Cerne, v. 1, n. 1, 1994. p. 64 -72.

OLIVEIRA-FILHO, A. T. et al. Estrutura fitossociológica e variáveis ambientais em um trecho da mata ciliar do córrego dos Vilas Boas, Reserva Biológica do Poço Bonito, Lavras (MG). Revista Brasileira de Botânica, v. 17, n 1, p. 67-85. 1994a.

OLIVEIRA-FILHO, A. T. et al. Effects of soils and topography on the distribution of tree species in a tropical riverine forest in south-eastern Brasil. Journal of Tropical Ecology, v. 10, n. 4, p. 483-508, 1994b. 
PEREIRA, J. A. A. Efeitos dos impactos ambientais $e$ da heterogeneidade ambiental sobre a diversidade e estrutura da comunidade arbórea de 20 fragmentos de florestas semidecíduas da região do Alto Rio Grande, Minas Gerais. 2003, 156 f. Tese (Doutorado em Ecologia, Conservação e Manejo da Vida Silvestre) - Universidade Federal de Minas Gerais, Belo Horizonte, 2003.

PEREIRA, J. A. A.; BOTELHO, S. A.; DAVIDE, A. C. Desenvolvimento de espécies florestais de rápido crescimento em diferentes condições de sítio visando a recomposição de matas ciliares. Cerne, v. 5, n. 1, 1999. p. 36-51.

PIÑA-RODRIGUES, F. C. M.; COSTA, L. G. S.; REIS, A. Estratégias de estabelecimento de espécies arbóreas e o manejo de florestas tropicais. In: CONGRESSO FLORESTAL BRASILEIRO, 6., 1990, Campinas. Anais... São Paulo: SBS/SBEF, 1990. p. 676-684.

PINTO, L. V. A. Caracterização física da bacia hidrográfica do Ribeirão Santa Cruz, Lavras-MG, e propostas de recuperação de suas nascentes. 2003, 171f. Dissertação (Mestrado em Engenharia Florestal) - Universidade Federal de Lavras, Lavras, 2003.

PINTO, L. V. A. et al. Estudo das nascentes da bacia hidrográfica do Ribeirão Santa Cruz, Lavras, MG. Scientia Forestalis, n. 65, p. 197-206, 2004a.

PINTO, S. I. C.; SOUZA, A. M.; CARVALHO, D. Variabilidade genética por isoenzimas em populações de Copaifera langsdorffii Desf. em dois fragmentos de mata ciliar. Scientia Forestalis, n. 65, p. 40-48, 2004 b.

RODRIGUES, R. R.; GANDOLFI, S. Conceitos, tendências e ações para a recuperação de florestas ciliares. In: RODRIGUES, R. R.; LEITÃO FILHO, H. Matas ciliares: conservação e recuperação. 2. ed. São Paulo: Universidade de São Paulo/Fapesp, 2001. p. 35-247.
RODRIGUES, R. R.; NAVE, A. G. Heterogeinidade florística das matas ciliares. In: RODRIGUES, R. R.; LEITÃO FILHO, H. Matas ciliares: conservação e recuperação. 2. ed. São Paulo: Universidade de São Paulo/Fapesp, 2001. p. 45-71.

SILVA, V. F. Impacto do fogo na vegetação de um fragmento de florestta semidecídua no município de Ibituruna-MG. 2002. 73 f. Dissertação (Mestrado em Ciências Florestais) - Universidade Federal de Lavras, Lavras, 2002.

SIMÕES, L. B. Integração entre um modelo de simulação hidrológica e sistema de informação geográfica na delimitação de zonas tampão ripárias. 2001. $171 \mathrm{f}$. Tese (Doutorado em Agronomia) Universidade Estadual de São Paulo, Botucatu, 2001.

SOUZA, J. S. Análise das variações

florísticas e estruturais da comunidade arbórea de um fragmento de floresta semidecídua às margens do Rio Capivari, Lavras, MG. 2001. 75 f. Dissertação (Mestrado em Ciências Florestais) Universidade Federal de Lavras, Lavras, 2001.

SWAINE, M. D.; WHITMORE, T. C. On the definition of ecological species groups in tropical rain forest. Vegetation, v. 75, n. 2, p81-86, 1988.

VAN den BERG, E. Estudo florístico e fitossociológico de uma floresta ripária em Itutinga - MG, e análise das correlações entre variáveis ambientais e a distribuição das espécies de porte arbóreo-arbustivo. 1995, 73 p. Dissertação (Mestrado em Ciências Florestais) Universidade Federal de Lavras, Lavras, 1995.

VELOSO, H. P.; RANGEL FILHO, A. L. R.; LIMA, J. C. A. Classificação da vegetação brasileira, adaptado a um sistema universal. [ s. 1. ]: IBGE, 1991. 123 p.

ZAKIA, M. J. B. Identificação e caracterização da zona ripária em uma bacia hidrográfica experimental: implicações no manejo de bacias hidrográficas e na recomposição de florestas. 1998.98 f. Tese (Doutorado em Ciências da Engenharia Ambiental) - Universidade Paulista, São Carlos, 1998.

R. Árvore, Viçosa-MG, v.29, n.5, p.775-793, 2005 